NBER WORKING PAPER SERIES

\title{
LOCKED UP BY A LOCKUP: VALUING LIQUIDITY AS A REAL OPTION
}

\author{
Andrew Ang \\ Nicolas P.B. Bollen \\ Working Paper 15937 \\ http://www.nber.org/papers/w15937
NATIONAL BUREAU OF ECONOMIC RESEARCH
1050 Massachusetts Avenue
Cambridge, MA 02138
April 2010

The authors thank an anonymous referee, the editor, Emanuel Derman, Greg van Inwegen, Jacob Sagi, Hans Stoll, Neng Wang, seminar participants at Columbia University's Financial Engineering Practitioners Seminar, Cornell University, the University of Mississippi, Vanderbilt University, and Virginia Tech, as well as attendees of the 1st Conference on the Econometrics of Hedge Funds (Paris) and the 3rd Conference on Professional Asset Management (Rotterdam) for helpful comments. Support from the Financial Markets Research Center and the Center for Hedge Fund Research (CHFR) at Imperial College London is gratefully acknowledged. The views expressed herein are those of the authors and do not necessarily reflect the views of the National Bureau of Economic Research.

NBER working papers are circulated for discussion and comment purposes. They have not been peerreviewed or been subject to the review by the NBER Board of Directors that accompanies official NBER publications.

(C) 2010 by Andrew Ang and Nicolas P.B. Bollen. All rights reserved. Short sections of text, not to exceed two paragraphs, may be quoted without explicit permission provided that full credit, including (C) notice, is given to the source. 
Locked Up by a Lockup: Valuing Liquidity as a Real Option

Andrew Ang and Nicolas P.B. Bollen

NBER Working Paper No. 15937

April 2010

JEL No. G11,G23,G24,G32,G33

\section{ABSTRACT}

Hedge funds often impose lockups and notice periods to limit the ability of investors to withdraw capital. We model the investor's decision to withdraw capital as a real option and treat lockups and notice periods as exercise restrictions. Our methodology incorporates time-varying probabilities of hedge fund failure and optimal early exercise. We estimate a two-year lockup with a three-month notice period costs approximately $1 \%$ of the initial investment for an investor with CRRA utility and risk aversion of three. The cost of illiquidity can easily exceed $10 \%$ if the hedge fund manager can arbitrarily suspend withdrawals.

Andrew Ang

Columbia Business School

3022 Broadway 413 Uris

New York, NY 10027

and NBER

aa610@columbia.edu

Nicolas P.B. Bollen

Vanderbilt University

Owen Grad School of Management

401 21st Avenue South

Nashville, TN 37203

nick.bollen@owen.vanderbilt.edu 
Hedge funds and funds-of-funds, along with many other alternative investment vehicles, place a variety of restrictions on the ability of investors to redeem their capital. A lockup requires an investor to wait a specified length of time after the initial deposit of capital, typically one to three years, before requesting a redemption. A notice period requires an investor to wait a specified length of time, typically one to three months, before a redemption request is processed. In addition, fund managers often have the authority to process only a fraction of a redemption request, known as a gate, or to suspend redemptions altogether. As argued by Aragon (2007), the advantage of redemption restrictions is that they allow fund managers to invest in illiquid assets and earn an associated return premium. Redemption restrictions can levy an important cost if they prevent investors from withdrawing capital before anticipated losses are realized. ${ }^{1}$ Our goal is to develop a methodology to estimate the implied cost of redemption restrictions, thereby allowing investors to more accurately tabulate hedge fund fees.

We model the ability of a risk-averse investor to withdraw capital as a real option. Upon exercise, the investor gives up ownership in the fund and receives a cash payoff per share equal to the fund's net asset value (hereafter "NAV"). The investor exercises the option when the investor's own valuation of a share of ownership in the fund, expressed as a certainty equivalent, falls below the NAV. We assume investors value the fund taking into account the probability of fund failure, liquidation costs, and the impact of future exercise decisions. These considerations are not completely captured in the fund's NAV. Redemption restrictions, such as lockups and notice periods, constrain the investor's ability to exercise, and their cost can be measured by the resulting reduction in value of the "liquidity option.",

\footnotetext{
${ }^{1}$ The case of Amaranth Advisors is a good example as described in “At Hedge Funds, Study Exit Guidelines," Wall Street Journal 10/23/06.

${ }^{2}$ See Longstaff (1995), Scholes (2000), Bollen, Smith, and Whaley (2004), and Chacko, Jurek, and Stafford (2008) for examples of liquidity options in other contexts.
} 
Our approach has three key elements. First, for the liquidity option to have value, there must be a difference between the NAV and an investor's valuation of ownership in the fund. In our model, an investor's valuation of ownership in the fund differs from the NAV as the NAV reflects neither the capitalization of future managerial performance nor the probability of fund failure and the associated liquidation cost. ${ }^{3}$

Second, we employ a data generating process (hereafter "DGP”) for hedge fund returns that includes a normal regime with a constant expected return and an absorbing failure state in which investors are forced to accept a payout per share equal to a fraction of the fund's NAV. Motivated by Gregoriou (2002) and Grecu, Malkiel, and Saha (2007), who find that most hedge funds stop reporting to databases due to failures following low returns, we use a log-logistic duration function to predict hedge fund failure and allow hazard rates to depend on realized performance. Specifically, the probability of fund failure, and, consequently, the value of a liquidity option, changes over time as a function of fund age and performance so that a fund with poor cumulative performance relative to its peers is more likely to fail.

Third, we model the payoff of investing in a hedge fund with and without a liquidity option using a binomial lattice that embeds time-varying probabilities of fund failure and, most importantly, allows for early exercise. This methodology accommodates failure probabilities that change as the hedge fund ages and increase when past returns are relatively poor. We measure the cost of a lockup as the difference between the value of a liquidity option that allows exercise at any time and another that does not permit exercise during the lockup. Similarly, we measure the cost of a notice period as the difference between the values of two liquidity options. The first

\footnotetext{
${ }^{3}$ The NAV could also differ from an investor's valuation if there is a difference of opinion regarding the prices of securities in the portfolio. For example, if the fund is invested in illiquid assets for which market prices are not readily available, the fund manager may employ subjective marking to model when computing the fund's NAV. See, for example, Asness, Liew, and Krail (2001), Getmansky, Lo, and Makarov (2004), and Bollen and Pool (2008).
} 
liquidity option generates a payoff equal to the fund NAV immediately upon exercise. The second liquidity option generates an uncertain payoff because the redemption is not processed until the notice period has elapsed. During the notice period, the NAV can rise or fall and the fund may fail; therefore, the two liquidity options can have different payoffs. We also compute the combined cost of lockups and notice periods.

Since liquidity is a real option that cannot be replicated by dynamic positions in the underlying hedge fund, standard option pricing techniques are inappropriate. Instead, our methodology values these options from a risk-averse investor's perspective using utility certainty equivalents. For a risk-neutral investor, this valuation method reduces to form expectations of payoffs.

We estimate the cost of lockups and notice periods by calibrating our model to a large sample of hedge funds using the CISDM database. Parameters for the log-logistic duration function indicate that there is a $50 \%$ chance a fund will fail by age 78 months, with failures clustering in the first few years. A fund with a cumulative return that falls one standard deviation below the cross-sectional mean has a 38\% increased risk of failure. We estimate that the combined cost of a two-year lockup and a three-month notice period is approximately $1 \%$ of the initial investment for a CRRA investor with risk aversion level of three. More risk-averse investors assign higher costs to the restrictions as they tend to want to liquidate sooner. As such, exercise restrictions are binding more often. Furthermore, we demonstrate that a manager's discretion to block redemption requests using gate restrictions or suspension clauses generates an implied cost that can easily exceed $10 \%$ of the initial investment, even for low levels of risk aversion. 
The rest of the paper is organized as follows. Section I discusses the correlations between our paper and existing research. Section II presents the DGP of hedge fund returns and demonstrates how we value lockups and notice periods. The data and the calibrated DGP are described in Section III. Section IV computes the cost of lockups and notice periods over a range of inputs. Section V provides our conclusions.

\section{Related Literature}

Our study of the ability of hedge fund investors to withdraw capital is related to existing research that models liquidity as a real option. Scholes (2000), for example, describes the need for liquidity during market downturns as a put option while Longstaff (1995) estimates the cost of the inability to sell a security for a certain period. More recently, Longstaff (2009) introduces the idea of modeling illiquidity as an investment problem in which the decision to buy or sell is irreversible. Options also arise in other contexts associated with the provision of liquidity. Bollen et al. (2004) demonstrate that part of the bid-ask spread set by a market maker for inventoryholding and adverse selection costs can be modeled as an option with a stochastic time to expiration.

Other related literature considers the cost of bearing illiquid asset positions. For example, Detemple and Sundaresan (1999) and Kahl, Liu, and Longstaff (2003), among many others, consider the problem of executive compensation where over an initial horizon, an agent is forced to hold restricted stock. There are several important differences between our approach and this literature. First, the executive compensation literature does not take into account default, which is a major driver of the cost of liquidity restrictions in our hedge fund setting. Second, the hedge 
fund liquidity restrictions cannot be hedged by trading in the underlying hedge fund. Third, we value liquidity options assuming an initial investment has already been made in the hedge fund. We deliberately do not solve the more complicated problem of taking into account the liquidity costs of hedge funds in a full scale asset allocation problem. ${ }^{4}$ Minimum investments in hedge funds are very large and a typical allocation, especially for a small institutional investor or a wealthy individual investor, represents a non-divisible allocation. Thus, the optimal allocation will often involve a binary outcome of investing or not investing in the hedge fund. Even for large investors, the decision is often to completely redeem, not to partially reduce, investment in a fund with poor performance. ${ }^{5}$

Naturally, as we indicate in our results, the liquidity option values can be used for the initial investment decision (i.e., an investor should invest if their valuation exceeds the NAV). However, our main analysis computes the cost of lockups and notice periods by comparing the values of hedge funds with and without restrictions. This comparison is directly relevant for accounting regulations such as FAS No. 157, “Fair Value Measurements,” of the Financial Accounting Standards Board that requires discounts for illiquidity be reflected when valuing existing positions in hedge funds and other illiquid vehicles.

Investors in our model exercise their redemption option when their own valuation of ownership in the fund falls below a hedge fund's NAV. This makes our model similar to the closed-end mutual fund (hereafter "CEF”) literature. Investors in CEFs can never redeem capital from a fund and instead trade shares of ownership on the secondary market where they typically

\footnotetext{
${ }^{4}$ Portfolio positions taking into account hedge fund illiquidity can be very different from portfolio positions where illiquidity is not considered as shown by Garleanu (2009). Thus, in a total portfolio context, the cost of illiquidity could be even larger than for a single hedge fund taken in isolation.

${ }^{5}$ For example, the extremely large Norwegian sovereign fund recently dropped 16 of the 22 external fixed income managers for poor performance rather than partially reduce allocations in these funds. See "In Europe, Are 'Active' Managers Worth It?” Wall Street Journal, June 3, 2009.
} 
observe a difference between NAV and the market price. The price is usually below the NAV and the difference is labeled the CEF discount. Berk and Stanton (2007) model the CEF discount as managerial ability to deliver abnormal returns net of fees, whereas Cherkes, Sagi, and Stanton (2009) model the CEF discount as a liquidity benefit net of fees. The liquidity benefit arises when the fund is invested in underlying illiquid securities that are costly to trade. Similar to these authors, we model a difference between the hedge fund NAV and the investor's value of the hedge fund, with the investor's valuation incorporating the net of after fee abnormal returns and the cost of fund failure.

Our paper differs fundamentally from the literature on CEF pricing on two dimensions. First, unlike CEF investors, hedge fund investors have the ability to exchange shares for NAV, although that ability is often restricted. Second, we model the investor's decision to redeem capital in the presence of time-varying probabilities of fund failure and risk aversion. In our model, an investor's decision to redeem is an optimal exercise of a real option which is affected by a fund failure process dependent on past performance.

Our paper is also related to existing studies regarding the relationship between redemption restrictions and hedge fund returns. Ding, Getmansky, Liang, and Wermers (2007) confirm that redemption restrictions affect the empirical cross-sectional correlation between aggregate capital flow and returns. Aragon (2007) documents that hedge funds with lockups have expected returns that are 4\%-7\% per annum higher than hedge funds without lockups. Aragon (2007) interprets this difference as an illiquidity premium. Lockups allow managers to invest in more illiquid securities and earn higher returns as a result. However, Aragon (2007) does not explicitly compute the cost of a lockup and cannot determine if the illiquidity premium is fair compensation for bearing the liquidity restriction. Related literature explores whether lockup 
provisions are a component of an optimal incentive contract for a fund manager, especially one investing in illiquid assets, as in Lerner and Schoar (2004).

Our paper is most closely related to Derman (2007), who models hedge fund returns using a three-state model in which hedge funds are good, sick, or dead. Derman, Park, and Whitt (2009) extend this approach to allow for more complex Markov chain models. In both approaches, lockups prevent an investor from withdrawing capital from a sick fund and investing the proceeds in a good fund. Our valuation strategy differs from Derman (2007) in four ways. First, Derman (2007) assumes investors swap capital invested in a poorly performing hedge fund for capital invested in a superior hedge fund, whereas we assume investors withdraw capital as cash. The cash proceeds can be used to invest in another hedge fund, but they can also be used for consumption or other investments. Thus, our approach explicitly models the actual decision that investors face. Second, we compute the costs of illiquidity born by a risk-averse CRRA investor. Third, we differentiate between lockups and notice periods and develop a methodology that can estimate the cost of the two restrictions separately or in combination. Finally, we model fund failure using a hazard rate that can be dependent upon fund age and performance, as described next.

\section{Methodology}

In this section, we use a binomial lattice to model the stochastic evolution of fund NAVs conditional on a fund surviving. We then augment the binomial lattice to incorporate default probabilities. Finally, we explain how to use the augmented binomial lattice to value hedge funds with and without liquidity options and how to estimate the cost of illiquidity by comparing hedge fund values when the liquidity option is restricted by a lockup, a notice period, or both. 


\section{A. Modeling Fund NAVs}

We assume that continuously compounded fund NAV returns are initially normally distributed and that this "normal regime” continues as long as the fund survives. We use a binomial lattice to model the evolution of a hedge fund's NAV. ${ }^{6}$ Let $S_{t, j}$ denote the NAV, where $t$ denotes the time step, running from zero to $T$, and $j$ denotes the level in the lattice, running from one to $t+1$ at time step $t$, with one being the highest as depicted in Figure I. We refer to the combination of time step $t$ and level $j$ as node $(t, j)$. The time between nodes is denoted by $\Delta t$.

Date $T$ represents the end of the hedge fund's life if failure never occurs. This can be interpreted as either the investor's investment horizon, the retirement of the hedge fund manager, or the feasible horizon of the fund's investment strategy and the purposeful unwinding of the hedge fund's positions.

Insert Figure I about here.

The geometry of the lattice is defined by step size $u$ and branch probability $p$, which are determined by setting the mean and variance implied by the lattice equal to those of the hedge fund's normal regime. With probability $p$, the NAV increases from $S_{t, j}$ to $S_{t+1, j}$ where:

$$
S_{t+1, j}=S_{t, j} u
$$

\footnotetext{
${ }^{6}$ Alternative distributional assumptions for the normal regime can be accommodated by increasing the number of branches emanating from each node and using a more elaborate lattice topology as in Hull and White (1993).
} 
with the multiplicative increase $u$ and the probability $p$ given by:

$$
\begin{aligned}
& u=e^{\sigma \sqrt{\Delta t}} \\
& p=\frac{e^{\mu \Delta t}-u^{-1}}{u-u^{-1}}
\end{aligned}
$$

where $\mu$ and $\sigma$ are the mean and standard deviation of hedge fund returns in the normal regime. With probability $1-p$, the NAV decreases from $S_{t, j}$ to $S_{t+1, j+1}$ where:

$$
S_{t+1, j+1}=S_{t, j} u^{-1}
$$

The parameters in Equation (2) ensure that the distribution of NAV returns implied by the lattice converge to the assumed normal distribution as $\Delta t \rightarrow 0$.

The NAV is of central concern as this is the quantity received by the investor upon redemption contingent on the fund not failing. Furthermore, the NAV is empirically convenient since hedge funds report NAV returns to hedge fund databases. As described next, we model failure to be a function of fund age and performance, as measured by cumulative NAV returns relative to competing funds.

\section{B. Failure Process}

Let $D$ be the duration of a hedge fund, which we define as the random time that a fund fails, and at which point the manager liquidates the fund's remaining assets. ${ }^{7}$ Empirically, we

\footnotetext{
${ }^{7}$ We do not model the strategic interactions in a liquidating event as in Cherkes et al. (2009), but our empirically estimated failure rate's sensitivity to performance may capture some of this effect.
} 
measure duration as the time that a hedge fund manager stops reporting returns. While some hedge fund managers may stop reporting for good performance, the majority of funds cease reporting due to failure as argued by Ackermann, McEnally, and Ravenscraft (1999) and Grecu et al. (2007). In practice, a failing fund could continue to survive for some period of time after the manager stops reporting. Consequently, our measure likely understates durations. If the fund fails at node $(t, j)$, we assume that the fund NAV drops to a level $S_{t, j} l$ where $l$ represents the proportion of pre-failure NAV that the manager is able to raise through liquidating asset sales with $0<l<1$. The investor receives the liquidating dividend at time $t+1$.

Our model of the hedge fund failure process extends the Markov chain model employed by Derman et al. (2009) to shift the baseline default intensity up and down by a performance covariate. Denote the baseline density of durations as $f_{b}(t)$ with cumulative density function $F_{b}(t)=\int_{0}^{t} f_{b}(s) d s$. The baseline survival function, $1-F_{b}(t)$, is the unconditional probability of surviving up to at least time $t$, evaluated at time zero. The baseline hazard rate at time $t$ is the probability of failure per time increment conditioned on surviving until $t:^{8}$

$$
\lambda_{b}(t)=\lim _{\Delta t \rightarrow 0} \frac{\operatorname{Pr}(t \leq D \leq t+\Delta t \mid D \geq t)}{\Delta t}=\frac{f_{b}(t)}{1-F_{b}(t)}
$$

Grecu et al. (2007) find the log-logistic distribution fits the empirical density of hedge fund durations better than other distributions; therefore, we use a log-logistic hazard rate function to

\footnotetext{
${ }^{8}$ Hazard rate models have been used in the statistical and epidemiological literature since the 1970s. We use the Cox relative risk model. Recent applications of similar hazard rate models are now being used in the credit literature, for example, Duffie, Wang and Saita (2007).
} 
model hedge fund failures. ${ }^{9}$ The log-logistic distribution is defined by two parameters, $\lambda$ and $q$, with density, survival function, and hazard rate given by:

$$
\begin{aligned}
f_{b}(t) & =\lambda q(\lambda t)^{q-1} /\left[1+(\lambda t)^{q}\right]^{2} \\
1-F_{b}(t) & =1 /\left[1+(\lambda t)^{q}\right] \\
\lambda_{b}(t) & =\lambda q(\lambda t)^{q-1} /\left[1+(\lambda t)^{q}\right] .
\end{aligned}
$$

We estimate $\lambda$ and $q$ by maximum likelihood. We separate hedge fund durations into $n$ uncensored observations, for which the hedge fund manager stopped reporting prior to the end of the database, and $m$ censored observations from "live" funds with observations through the end of the database. The likelihood of the data is then given by:

$$
\prod_{i=1}^{n} f\left(t_{i}\right) \prod_{j=1}^{m}\left(1-F_{b}\left(t_{j}\right)\right)
$$

with durations $t_{i}$ for the $n$ funds leaving the database and durations $t_{j}$ for the $m$ funds surviving until the end of the sample. This yields a log-likelihood of:

$$
n \ln (\lambda q)+(q-1) \sum_{i=1}^{n} \ln \left(\lambda t_{i}\right)-2 \sum_{i=1}^{n} \ln \left(1+\left(\lambda t_{i}\right)^{q}\right)-\sum_{j=1}^{m} \ln \left(1+\left(\lambda t_{j}\right)^{q}\right)
$$

\footnotetext{
${ }^{9}$ In Section III, we present evidence that the log-logistic hazard rate function provides a tight fit to the empirical distribution of hedge fund failures in our sample.
} 
We assume that failure rates also depend on hedge fund cumulative performance relative to other funds. Specifically, the hazard rate of an individual hedge fund equals the baseline hazard rate scaled up or down depending on the value of covariate $z$ as follows:

$$
\lambda(t ; z)=\lambda_{b}(t) e^{z \beta}
$$

We follow standard practice and demean the covariate so that values above or below zero increase or decrease the hazard rate. We choose a performance-based covariate equal to the difference between the cumulative return of fund $i$ at time $t$ and the cross-sectional mean return. The difference is then scaled by the cross-sectional standard deviation. The cross-sectional mean and standard deviation are computed using the cumulative returns of each fund when they are the same age as fund $i$ at time $t$.

The sensitivity of the failure rate to performance can be motivated in at least three ways. First, and most importantly, Liang (2000), Brown, Goetzmann, and Park (2001), and Jagannathan, Malakhov, and Novikov (2009), among others, empirically document that liquidated hedge funds are more likely to be funds with poor past performance. Second, managers of funds with low cumulative returns are less likely to capture performance fees since the NAV must recover to previously set high-water marks before the fees accrue. This provides managers of poorly performing funds a strong incentive to close those funds. Third, investors are more likely to withdraw capital from poorly performing funds forcing the manager to liquidate assets which could lead to further reductions in NAV causing the manager to close those funds. ${ }^{10}$

\footnotetext{
${ }^{10}$ As reported in Ding et al. (2007), academic evidence regarding the flow-performance correlation in hedge funds is mixed with prior research finding linear, convex, and concave relationships between fund flow and performance. Ding et al. (2007) argue that the presence of redemption restrictions can explain these results.
} 
The form of the proportional hazard rate in Equation (8) is convenient because the coefficient $\beta$ can be estimated independently from the baseline hazard rate as noted by Kalbfleisch and Prentice (2002). In particular, the relevant partial likelihood can be expressed as:

$$
\prod_{i=1}^{n}\left[e^{z_{i} \beta}\left[\sum_{k=1}^{N_{i}} e^{z_{k} \beta}\right]^{-1}\right]
$$

where $n$ is the number of uncensored observations, or fund failures, in the sample, $z_{i}$ is the value of the performance covariate at failure of fund $i, N_{i}$ is the number of funds in the sample with durations at least as long as that of fund $i$, and $z_{k}$ is the value of the performance covariate of fund $k$ evaluated at an age equal to that of fund $i$ at the time of failure of fund $i$.

The hazard rate in Equation (8) allows for the probability of failure to depend nonlinearly on age and the realized performance of the fund. In many option applications, statedependent payoffs lead to path dependence and cause the number of nodes in a lattice to explode. A major advantage of our approach is that we specify the performance covariate so that it can be computed at each node in the lattice without knowledge of the path taken. This allows timevarying default rates by modeling only one state variable. Without this innovation, incorporating default as a function of past returns would require onerous simulation methods.

Let $\pi_{t, j}$ denote the probability of failure at node $(t, j)$ with the failure occurring prior to the return of the fund being realized between time $t$ and $t+1$. At node $(t, j)$, we numerically evaluate this by setting $\pi_{t, j}=\lambda_{b}\left(\operatorname{age}_{t}+0.5\right) \Delta t$ in the case of the base hazard rate and $\pi_{t, j}=\lambda_{b}\left(\right.$ age $\left._{t}+0.5\right) e^{z_{t, j} \beta} \Delta t$ in the case of the proportional hazard rate, where $\Delta t$ is the increment 
of time in the lattice, $z_{t, j}$ is the value of the performance covariate at node $(t, j)$, and age $e_{t}$ is the age of the fund at time $t$. The hazard rates over $t$ to $t+\Delta t$ depend on the value of the covariate at t. Evaluating the baseline hazard rate at the midpoint amounts to taking the integral over $t$ to $t+\Delta t$. Note that time $t=0$ corresponds to the investor's initial subscription to the fund rather than the fund's age. If the fund has already been in existence for some period of time, its cumulative return from the inception of the fund impacts the value of $\pi_{0,1}$ since both the cumulative relative performance, $z$, as well as the baseline hazard function, $\lambda_{b}$, depend on the fund's age.

\section{Valuing Liquidity Options}

We have described the evolution of a hedge fund's NAV. But what is the fund worth to an investor? An investor's own valuation may differ from the NAV for a number of reasons. The investor's valuation incorporates risk aversion, the mean and variance of fund returns, as well as the probability that the hedge fund will fail in the future resulting in an associated liquidation cost. ${ }^{11}$ When there are no binding liquidity restrictions, hedge fund investors have a real option to give up their ownership and receive the NAV. Investors exercise when the current NAV exceeds the certainty equivalent of holding the hedge fund. ${ }^{12}$

\footnotetext{
${ }^{11}$ Our pricing methodology does not assign any premium to an investor requiring immediate access to invested capital during the lockup period for exogenous reasons. Incorporating exogenous liquidity demands would increase the cost of lockups and notice periods. Note that our liquidity option is not a fully redundant security as in standard risk-neutral option valuation. Our option values are real options computed using utility certainty equivalent values under the real measure. We do not use risk-neutral valuation techniques to value these options since the underlying asset cannot be dynamically hedged.

${ }^{12}$ If investors were identical, they would all decide to withdraw simultaneously forcing the manager to liquidate the fund so that all investors would bear the liquidation cost. In practice, investors are not identical because some will be subject to lockups and others will not, depending on when they entered the fund. Some investors may also be better informed than other investors or may possess different priors regarding the DGP of returns.
} 
When an investor redeems, he is exchanging a share of ownership in the fund for its NAV. One might think the redemption is the exercise of an exchange option as in Margrabe (1978). Indeed, Derman (2007) explicitly models the exchange of an ownership in a bad fund for ownership in a good fund and computes the cost of a lockup as the inability to exchange a good fund for a bad fund during a fixed time period. In Margrabe’s (1978) model, the option holder exchanges one risky asset for another. Both assets are governed by a distinct, but correlated stochastic process. In our model, however, the investor's valuation of the fund is an explicit function of the NAV. Only the NAV's stochastic process is necessary. In addition, since the investor exchanges ownership for cash, a more appropriate analog is a put option in which the investor can sell the share of ownership back to the fund for the NAV. The NAV is, of course, constantly changing. As such, the liquidity option can be viewed as a put option with a variable exercise price.

We assume that investors are risk-averse with a CRRA utility function for time $T$ wealth, $W_{T}$, given by:

$$
U\left(W_{T}\right)=W_{T}^{1-\gamma} /(1-\gamma)
$$

where $\gamma$ is the agent's risk aversion. We expect, and confirm in Section IV, that more risk-averse investors assign a higher cost to lockups and redemption periods than less risk-averse investors. This is similar to the literature regarding executive stock options (ESOs) that demonstrates that the value of an ESO to a manager who cannot short the underlying stock is affected by risk aversion. ${ }^{13}$ Higher risk aversion coincides with a greater likelihood that constraints bind thereby

\footnotetext{
${ }^{13}$ See, among others, Kulatilaka and Marcus (1994), Detemple and Sundaresan (1999), and Murphy (1999).
} 
reducing the ESO value. Similarly, higher risk aversion causes the restrictions on exercise imposed by lockups and notice periods to bind more often. This increases the cost of lockups and notice periods.

\section{Hedge Fund Value with No Liquidity Option}

Let $H_{t, j}$ denote the value of a hedge fund per share conditional on survival at node $(t, j)$ from the perspective of a "passive" investor who does not possess a liquidity option. The passive investor is an artifice necessary to compute the value of liquidity options as shown below. In addition, note that a fund manager can unilaterally impose restrictions on exercise that reduce the value of an investor's liquidity option, and, in the extreme case, can eliminate the liquidity option completely. Here is an excerpt from an actual partnership agreement that is typical of many suspension clauses employed by hedge funds:

The Fund may suspend redemptions and defer payment of redemption proceeds during any period in which disposal of all or part of the Fund's assets, or the determination of Net Asset Value, would not be reasonable or practical or would be prejudicial to the Fund or the Shareholders.

During times of high demand for the withdrawal of capital, for example, managers may temporarily suspend redemptions to avoid high transaction costs, such as price impact or fire sales incurred when selling fund assets. Thus, $H_{t, j}$ represents the lower bound on the value of the hedge fund to an investor who possesses a liquidity option. This bound would be reached when the fund manager suspends redemptions when it is optimal for the investor to withdraw. In 
other words, we can interpret $H_{t, j}$ as the extreme case when a hedge fund manager disables an investor's liquidity option.

A passive investor will receive a payoff at the time of fund failure or at date $T$ if the fund survives until the end of the investment horizon. For simplicity, we assume that if the fund fails, the investor places the proceeds in a risk free account until time $T$. Assume that at the terminal set of nodes, investors receive the NAV, $S_{T, j}$. This assumption could easily be relaxed to allow for the cost of unwinding existing positions in the fund at the terminal date.

Prior to the terminal set of nodes, the value of the investment conditional on survival is given by its certainty equivalent, which we define as the current value of a risk free security that matures at time $T$ and provides a guaranteed level of utility equal to the expected utility of holding the hedge fund. At node $(T-1, j)$, the value of the fund, $H_{T-1, j}$, is the solution to:

$$
\frac{1}{1-\gamma}\left(R_{f} H_{T-1, j}\right)^{1-\gamma}=\frac{1}{1-\gamma}\left[\pi_{T-1, j}\left(S_{T-1, j} l\right)^{1-\gamma}+\left(1-\pi_{T-1, j}\right)\left(p S_{T, j}^{1-\gamma}+(1-p) S_{T, j+1}^{1-\gamma}\right)\right]
$$

where $R_{f}$ is the gross risk free return for a period of length $\Delta t$.

The RHS of Equation (11) is the expected utility of random time $T$ wealth computed at node $(T-1, j)$ when the NAV of the fund is $S_{T-1, j}$. The first term in square brackets allows for the probability that the fund fails between $T-1$ and $T$ resulting in a loss due to the liquidation cost and a payoff at $T$ equal to $S_{T-1, j} l$. The second term captures the expected utility of an investment in the fund if failure does not occur. The LHS of Equation (11) is the utility of a certain time $T$ wealth level $R_{f} H_{T-1, j}$ which gives the same expected utility as holding the hedge 
fund. We use $H_{T-1, j}$ to express the certainty equivalent of the hedge fund investment at node $(T-1, j)$, so that the investor is indifferent between staying in the fund at node $(T-1, j)$ and exchanging for cash equal to $H_{T-1, j}$, which is then deposited in a risk free account.

We can solve explicitly for the investor's valuation of the fund at node $(T-1, j)$ by rewriting Equation (11) as:

$$
H_{T-1, j}=R_{f}^{-1}\left[\pi_{T-1, j}\left(S_{T-1, j} l\right)^{1-\gamma}+\left(1-\pi_{T-1, j}\right)\left(p S_{T, j}^{1-\gamma}+(1-p) S_{T, j+1}^{1-\gamma}\right)\right]^{1 / 1-\gamma} .
$$

Prior to $T-1$, the computation is similar to Equation (12), but involves next period certainty equivalents:

$$
H_{t, j}=R_{f}^{-1}\left[\pi_{t, j}\left(S_{t, j} l\right)^{1-\gamma}+\left(1-\pi_{t, j}\right)\left(p H_{t+1, j}^{1-\gamma}+(1-p) H_{t+1, j+1}^{1-\gamma}\right)\right]^{1 / 1-\gamma}
$$

Under CRRA utility, the indirect utility is also of the power form, which permits using the certainty equivalent in Equation (12) in the computation of Equation (13). The recursion in Equation (13) is repeated until the initial node in the lattice is reached, where the value of the hedge fund to the investor is $H_{0,1}$.

Note that the approach outlined above nests the case of risk neutrality, which can be represented by setting $\gamma=0$. For a risk-neutral investor, the calculations in Equations (12) and (13) simply compute the discounted, expected payoff, where the discounting occurs at the risk free rate. 


\section{Hedge Fund Value with an Unrestricted Liquidity Option}

Let $O_{t, j}$ denote the value of the hedge fund per share at node $(t, j)$ conditional on survival, but this time from the perspective of an "active” investor who possesses an unrestricted liquidity option. We estimate the cost of lockups and notice periods, which impose restrictions on exercise, from the basis of this unrestricted liquidity option. The unrestricted liquidity option is defined as the ability to exchange a share in the hedge fund for the NAV at any time prior to the terminal set of nodes. The investor will exercise the option at a given node $(t, j)$ if an immediate payoff equal to the fund $\mathrm{NAV}, S_{t, j}$, provides greater utility than the expected utility of remaining in the fund.

As before, we assume that the investor receives the NAV at the terminal set of nodes. Prior to the terminal set of nodes, the hedge fund value is the maximum of immediate exercise of the redemption option and the certainty equivalent. At node $(T-1, j)$, the value of the fund, $O_{T-1, j}$, is the solution to:

$$
O_{T-1, j}=\max \left(S_{T-1, j}, R_{f}^{-1}\left[\pi_{T-1, j}\left(S_{T-1, j} l\right)^{1-\gamma}+\left(1-\pi_{T-1, j}\right)\left(p S_{T, j}^{1-\gamma}+(1-p) S_{T, j+1}^{1-\gamma}\right)\right]^{1 / 1-\gamma}\right)
$$

The first element in the RHS of Equation (14) is the value received by the investor upon immediate exercise, which is the NAV of the fund at the beginning of the node, $S_{T-1, j}$. The second term is the value of the fund to the investor expressed as a certainty equivalent computed 
at node $(T-1, j)$. If the investor obtains a higher utility by receiving the NAV, the investor exercises his option. Prior to time $T-1$, the option value is computed as:

$$
O_{t, j}=\max \left(S_{t, j}, R_{f}^{-1}\left[\pi_{t, j}\left(S_{t, j} l\right)^{1-\gamma}+\left(1-\pi_{t, j}\right)\left(p O_{t+1, j}^{1-\gamma}+(1-p) O_{t+1, j+1}^{1-\gamma}\right)\right]^{1 / 1-\gamma}\right) .
$$

The initial value of the hedge fund to the investor with an unrestricted liquidity option is $O_{0,1}$ and the initial value of the liquidity option is $\mathrm{O}_{0,1}-\mathrm{H}_{0,1}$.

\section{Valuing a Notice Period}

Let $O_{N P, t, j}$ denote the value of the hedge fund per share at node $(t, j)$, conditional on survival of the fund, when the liquidity option is subject to a notice period. The hedge fund value is generally reduced by the notice period because when the option is exercised at node $(t, j)$, the investor does not immediately receive a payoff, but rather must wait some period of time before receiving the prevailing NAV at that future date. The payoff may drop substantially if the fund fails while the investor waits. This is relatively likely as the investor chooses to exercise the option when the failure probability is high. ${ }^{14}$

Consider a one period delay between option exercise and receipt of the NAV. As before, we assume that the investor receives the NAV at the terminal set of nodes. With a one period notice, the option to redeem is irrelevant at the penultimate set of nodes. Thus:

\footnotetext{
${ }^{14}$ In practice, once a notice has been given, the investor can cancel the redemption up until the monies are due. Thus, notification is reversible. We do not model this additional option, but note that it makes the small notice period values we report conservative upper bounds.
} 


$$
O_{N P, T-1, j}=R_{f}^{-1}\left[\pi_{T-1, j}\left(S_{T-1, j}\right)^{1-\gamma}+\left(1-\pi_{T-1, j}\right)\left(p S_{T, j}^{1-\gamma}+(1-p) S_{T, j+1}^{1-\gamma}\right)\right]^{1 / 1-\gamma} .
$$

Prior to the penultimate set of nodes, however, the hedge fund value is given by the maximum of the certainty equivalent of exercising the liquidity option and the certainty equivalent of staying in the fund. If the investor exercises at node $(t, j)$, the certainty equivalent is a function of the NAV at time $t+1$ since there is a one period delay. We allow for the possibility that the fund fails while the investor is waiting, so that the certainty equivalent at node $(t, j)$ of exercising the liquidity option, denoted as $C E$, is:

$$
C E_{t, j}=R_{f}^{-1}\left[\pi_{t, j}\left(S_{t, j} l\right)^{1-\gamma}+\left(1-\pi_{t, j}\right)\left(p S_{t+1, j}^{1-\gamma}+(1-p) S_{t+1, j+1}^{1-\gamma}\right)\right]^{1 / 1-\gamma}
$$

Thus, the hedge fund value at node $(t, j)$ is:

$$
O_{N P, t, j}=\max \left\{C E_{t, j}, R_{f}^{-1}\left[\pi_{t, j}\left(S_{t, j} l\right)^{1-\gamma}+\left(1-\pi_{t, j}\right)\left(p O_{N P, t+1, j}^{1-\gamma}+(1-p) O_{N P, t+1, j+1}^{1-\gamma}\right)\right]^{1 / 1-\gamma}\right\} .
$$

If there is no notice period, $C E_{t, j}=S_{t, j}$ and Equation (18) reduces to Equation (15).

Longer notice periods can be incorporated by replacing the expression in Equation (17) with a sub-lattice that accounts for the possibility of failure at each time step. Consider an $m$ period delay in processing a redemption request that is made at node $(t, j)$. To value the hedge fund with an $m$-period notice at node $(t, j)$, we compute the certainty equivalent taking into 
account the possibility the fund fails over the next $m$ periods. The $C E$ with an $m$-period delay is computed in a recursive fashion, beginning with the set of $m+1$ NAVs that are possible in $m$ periods assuming that the fund survives the notice period. In $m$ periods, assuming the fund does not fail, the possible NAVs are $S_{t+m, j}$ through $S_{t+m, j+m}$. Moving back one time step, the $C E$ is computed at each node as follows:

$$
C E_{t+m-1, k}=R_{f}^{-1}\left[\pi_{t+m-1, k}\left(S_{t+m-1, k} l\right)^{1-\gamma}+\left(1-\pi_{t+m-1, k}\right)\left(p S_{t+m, k}^{1-\gamma}+(1-p) S_{t+m, k+1}^{1-\gamma}\right)\right]^{1 / 1-\gamma}
$$

where $k$ runs from $j$ to $j+m-1$. Moving back one more time step, $C E$ is computed at each node in a similar fashion:

$$
C E_{t+m-2, k}=R_{f}^{-1}\left[\begin{array}{l}
\pi_{t+m-2, k}\left(S_{t+m-2, k} l\right)^{1-\gamma}+ \\
\left(1-\pi_{t+m-2, k}\right)\left(p C E_{t+m-1, k}^{1-\gamma}+(1-p) C E_{t+m-1, k+1}^{1-\gamma}\right)
\end{array}\right]^{1 / 1-\gamma}
$$

where $k$ runs from $j$ to $j+m-2$. The computation in Equation (20) is then repeated for all remaining time steps in the notice period.

As before, we assume that the investor receives the NAV at the terminal set of nodes. When the notice requires a wait of $m$ periods, the option to file a notice does not exist in the $m$ steps prior to the terminal date $T$. That is, the hedge fund value is computed as in Equation (16) for date $T-1$ with:

$$
O_{N P, t, j}=R_{f}^{-1}\left[\pi_{t, j}\left(S_{t, j} l\right)^{1-\gamma}+\left(1-\pi_{t, j}\right)\left(p O_{N P, t+1, j}^{1-\gamma}+(1-p) O_{N P, t+1, j+1}^{1-\gamma}\right)\right]^{1 / 1-\gamma} .
$$


for $T-m \leq t \leq T-2$. Prior to this date, the investor decides whether or not to file a notice using the decision rule in Equation (18).

The initial value of the hedge fund to the investor with a liquidity option restricted by a notice period is $O_{N P, 0,1}$ and the initial value of the restricted liquidity option is $O_{N P, 0,1}-H_{0,1}$. Recall the initial value of the liquidity option with no redemption restriction is $O_{0,1}-H_{0,1}$. Thus, the cost imposed on the investor by the notice period is the difference between the unrestricted and restricted option (i.e., $O_{0,1}-O_{N P, 0,1}$ ). Therefore, the cost of the redemption notice is the difference between two liquidity options. The first provides a payoff equal to the NAV immediately upon exercise. The second provides a payoff equal to the prevailing NAV at the end of the notice period if the fund does not fail, or a payoff equal to a fraction of the prevailing NAV if the fund fails after the investor has requested a redemption, but prior to the end of the notice period.

\section{Valuing a Lockup}

A lockup prevents an investor from exercising his liquidity option prior to date $L$. Let $O_{L, t, j}$ denote the value of a hedge fund at node $(t, j)$ with a liquidity option restricted by a lockup, and $O_{L N P, t, j}$ denote the value subject to both a lockup and a notice period. After the lockup expires, there is no restriction. Therefore, $O_{L, t, j}=O_{t, j}$ and $O_{L N P, t, j}=O_{N P P, t, j}$ for $t>L$, and hedge fund values can be computed as described above. For $t \leq L$, however, the investor cannot exercise the liquidity option. Consequently: 


$$
\begin{aligned}
& O_{L, t, j}=R_{f}^{-1}\left[\pi_{t, j}\left(S_{t, j} l\right)^{1-\gamma}+\left(1-\pi_{t, j}\right)\left(p O_{L, t+1, j}^{1-\gamma}+(1-p) O_{L, t+1, j+1}^{1-\gamma}\right)\right]^{1 / 1-\gamma} \\
& \text { and } \\
& O_{L N P, t, j}=R_{f}^{-1}\left[\pi_{t, j}\left(S_{t, j} l\right)^{1-\gamma}+\left(1-\pi_{t, j}\right)\left(p O_{L N P, t+1, j}^{1-\gamma}+(1-p) O_{L N P, t+1, j+1}^{1-\gamma}\right)\right]^{1 / 1-\gamma}
\end{aligned}
$$

for $t \leq L$. The lockup restricts exercise of the liquidity option in the same way that a vesting period prevents exercise of ESOs as in Hull and White (2004).

The initial value of a hedge fund with a liquidity option subject to a lockup is $O_{L, 0,1}$ and the initial value of the restricted liquidity option is $O_{L, 0,1}-H_{0,1}$. The ex-ante cost of the lockup itself is the difference between the unrestricted and restricted options (i.e., $O_{0,1}-O_{L, 0,1}$ ). Similarly, the initial value of a hedge fund with a liquidity option subject to both a lockup and a notice period is $O_{L N P, 0,1}$ and the initial value of the restricted liquidity option is $O_{L N P, 0,1}-H_{0,1}$. The combined ex-ante cost of the lockup and notice period is the difference between the unrestricted and restricted options (i.e., $O_{0,1}-O_{L N P, 0,1}$ ).

\section{Summary}

Table I contains a summary of notations describing model parameters including expressions for the value of liquidity options and the cost of notice periods and lockups. The value of a liquidity option is computed as the difference between the hedge fund value with the liquidity option and the hedge fund value from the perspective of a passive investor with no liquidity option. The cost of a notice period or a lockup is computed as the difference between the hedge fund value with an unrestricted liquidity option and the hedge fund value with a liquidity option subject to the restriction. 
Insert Table I about here.

\section{Data and Parameter Estimates}

The hedge fund data used in our empirical analysis are from the Center for International Securities and Derivatives Markets (CISDM) database. The sample period runs through December 2005. The CISDM database includes live and defunct hedge funds, funds of funds, CTAs, commodity pool operators, and indices. We eliminate indices since they have no partners and, as such, no lockup feature. There are 4,260 defunct funds and 4,272 live funds in the sample with a total of 504,979 monthly observations.

Figure II presents the percentage of defunct funds at each possible duration as well as the percentage of live funds at each possible history length. The most common durations for defunct funds lie in the two- to four-year range suggesting that many funds fail early in their lives. The most common history length for live funds is one year or less, a result of the tremendous growth in the industry. Table II lists the interquartile range of the history lengths of live funds, defunct funds, and the full sample. The ranges are similar with medians of 44 months for live funds and 47 months for defunct funds. The hedge fund data are right-tailed censored because we only know the history of returns up until a fund stops reporting or until the end of the database is reached. Therefore, the expected duration of a fund will likely be much longer than these medians. This is verified by maximum likelihood estimates of the hazard rate function as described below.

Insert Figure II and Table II about here. 
Cross-sectional averages of annualized summary statistics of the monthly returns are listed in Table III. We require at least 24 observations for a fund to be included. A total of 3,287 defunct funds and 3,023 live funds, covering 476,178 monthly returns, are represented. The performance of defunct funds is clearly inferior and consistent with poor performance as a good predictor of fund failure. For example, defunct hedge funds have an annualized average return of $11.86 \%$ compared to $13.87 \%$ for live hedge funds. Sharpe (1992) ratios of defunct hedge funds average 0.63 versus 1.27 for live hedge funds. Note there is also substantial variation across fund types. In Panel C, for instance, hedge funds have annualized volatility of $15.74 \%$ compared to 22.57\% for CTAs. In unreported analysis, wide variation also exists across subsets of hedge funds formed by strategy. Thus, when computing the value of liquidity options and the cost of lockups and notice periods, it will be important to consider a wide range of parameters as there is great heterogeneity across hedge funds. As a base case, we use an expected return of $12 \%$ and volatility of $15 \%$ for the "normal regime."

Insert Table III about here.

Table IV lists parameter estimates of the hazard rate function. Parameters of the baseline $\log$-logistic function in Equation (5) are estimated very precisely, with $\lambda=0.0129$ and $q=$ 1.6517. The duration at which the unconditional probability of survival is $50 \%$ is given by $\lambda^{-1}$ equaling approximately 78 months. Thus, taking into account the large number of censored observations in the sample, the expected duration of a fund is much longer than the median 44month duration of live funds reported in Table II. Figure III compares the actual number of 
hedge funds with uncensored duration $t$ to the predicted number based on the parameter estimates of $\lambda$ and $q$. The predicted number equals the hazard rate evaluated at duration $t$ times the total number of funds, both live and defunct, with history length of at least $t$. The fit is good, with the sharp peak for short durations consistent with the empirical distribution of durations of defunct funds in Panel A of Figure II. This result suggests that fund age is a significant determinant of the probability that a manager will stop reporting to the database. The other determinant in our specification is the relative cumulative fund performance which shifts the baseline hazard rate up or down. Table IV reports the maximum likelihood estimate of $\beta$ is -0.3237 with a standard error of 0.0059 . Thus, a cumulative return that is one standard deviation below the mean increases the hazard rate by about $38 \%$.

Insert Table IV and Figure III about here.

Upon failure, we assume, as a base case, that investors receive a payoff of $l=75 \%$ of the prevailing NAV of the fund, reflecting an additional loss of asset value during liquidation. The $25 \%$ liquidation cost is based on results reported in Ramadorai (2008), who analyzes a sample of transactions on a secondary market for hedge fund investments conducted on Hedgebay. During 66 "disaster" transactions involving fraud or collapse, the average discount of transaction price to NAV is $49.6 \%$. It is likely that not all hedge fund liquidations incur losses this extreme as some managers are able to unwind positions in a deliberate manner. To be conservative, we halve 
Ramadorai's (2008) estimate, but examine sensitivity of lockup costs with respect to this parameter. ${ }^{15}$

\section{Value of Liquidity Options and the Cost of Restrictions}

\section{A. Cost of Lockups and Notice Periods}

Table V lists the combined costs of lockups and notice periods when initial fund NAV is $\$ 100$, returns are normally distributed with an annual expected return of $12 \%$ and volatility of $15 \%$, the fund has a ten-year horizon, fund failures incur a $25 \%$ loss upon liquidation, and the risk free rate is 4\%. Panel A reports results for new funds, while Panel B presents the outcomes when funds have an age equal to 24 months at $t=0$, both with risk aversion $\gamma=3$. Panel A indicates that costs are increasing with the length of the lockup and notice period. For a notice period of three months, the combined cost of restrictions ranges from $\$ 0.04$ for a one-year lockup to $\$ 2.13$ for a five-year lockup. For a lockup of three years, the combined cost of restrictions ranges from $\$ 0.68$ for a one-month notice period to $\$ 0.92$ for a five-month notice period. These results suggest that the length of the lockup has much more impact on the combined cost of restrictions than the length of the notice period. Introducing notice periods has only a small effect on hedge fund value as the probability of failure during the notice period is small.

Insert Table V about here.

\footnotetext{
${ }^{15}$ In conversations with fund-of-funds managers, our value of the NAV dropping 25\% contingent upon failure was remarked to be conservative, with their (informal) estimates closer to 50\%. Some failing funds have a drop of nearly $100 \%$ in value contingent upon default, even in cases not involving fraud. For example, investors in Citigroup’s Corporate Special Opportunities Fund received 3 cents on the dollar when the fund was wrapped up as reported in “Investors Hammered by Citi Fund Setback,” Financial Times, January 15, 2009.
} 
Panel B of Table V implies that slightly older funds generally have higher restriction costs. The intuition for this is that failure probabilities peak for funds that are a few years old, as indicated by Figure II. For a lockup of three years, for example, the combined costs range from \$1.21-\$1.39 over the notice periods when the fund is two years old, substantially more than the cost when funds are new.

\section{B. Comparative Statics}

We list in Table VI, the value of liquidity options and the cost of restrictions as a function of expected return, hazard rate, loss upon liquidation, volatility, and risk aversion. We report costs with a two-year lockup and a three-month notice period. The base case is a hazard rate equal to the empirical estimate, a loss upon liquidation equal to $25 \%$ of the prevailing $\mathrm{NAV}$, an annual volatility of $15 \%$, and a risk aversion of 3 .

Insert Table VI about here.

In all cases, liquidity option values and restriction costs are decreasing in expected return. The reason is that higher expected returns increase the expected utility of remaining in the fund, ceteris paribus.

Panels A1 and B1 report results for different hazard rates. The empirical estimate of the parameter $\lambda$ is scaled by a factor ranging from $50 \%-250 \%$. Liquidity option value and restriction costs are increasing in $\lambda$ because when the baseline hazard rate increases, the failure probability increases at every node. This decreases the expected utility of staying in the fund. For example, when $\mu=12 \%$ and $\lambda$ is 1.5 times its empirical estimate, the combined restriction costs are $\$ 2.81$, 
more than ten times the cost when the hazard rate equals its empirical estimate. Note that the cost of restrictions is essentially zero at all levels of expected return when the hazard rate parameter $\lambda$ is only $50 \%$ its empirical estimate. The reason for this is that at very low hazard rates, the probability that exercise will be optimal during the lockup period is negligible.

Panels A2 and B2 demonstrate results when $l$, the proportion of assets retained upon fund failure, is varied. Liquidity option value and the cost of restrictions are both decreasing in $l$ since the benefit of exercise is lower when losses due to failure are lower. When $\mu=12 \%$ and investors only recover $60 \%$ of $\mathrm{NAV}$, the restrictions cost $\$ 5.17$ as compared to the $\$ 0.03$ when investors recover $80 \%$ of NAV. For recovery rates greater than $80 \%$, the combined restriction costs are zero when expected returns are above $8 \%$. The greater sensitivity of lockup costs to $l$ is intuitive. If there is only a small loss in the NAV contingent upon default, the investor loses little in bearing the liquidity restriction. As $l$ decreases, the utility costs can become very large, especially for highly risk-averse investors.

Panels A3 and B3 present results when annual volatility in the normal regime ranges from 5\%-25\%. Both liquidity option value and the cost of restrictions are increasing in volatility. Higher volatility decreases expected utility for a risk-averse investor. In addition, higher volatility raises the failure probability following down steps since the fund return is further away from the cross-sectional mean. For instance, when $\mu=12 \%$ and annual volatility is $20 \%$, the combined restriction costs are $\$ 2.92$, more than ten times the cost when volatility equals $15 \%$.

Panels A4 and B4 also report results for different levels of risk aversion as measured by the parameter $\gamma$. Liquidity option values and restriction costs are substantially larger when risk aversion is high. The intuition is that as is the case with ESOs, higher levels of risk aversion tend to accelerate the exercise decision. This increases the likelihood that liquidity restrictions are 
binding. When $\mu=12 \%$ and risk aversion is 6 , for example, the combined restriction costs are $\$ 6.77$ compared to $\$ 0.71$ when risk aversion is 3.5.

\section{Underlying Hedge Fund Values}

The costs of hedge fund lockups and notice period restrictions reported thus far are differences between the values of hedge funds with and without exercise restrictions. We now examine the underlying hedge fund values to gain further insight. The underlying hedge fund values under various liquidity restrictions allow investors to compare their valuation of ownership in the fund. The initial investment decision would be attractive only if this valuation exceeds the initial NAV.

Table VII reports hedge fund values with and without restrictions, over a range of expected returns in the normal regime. Panel A lists hedge fund values when the fund has age = 0 at time $t=0$. The passive value of the hedge fund with no liquidity option, $H_{0,1}$, ranges from $\$ 81.40$ when $\mu=8 \%$ to $\$ 121.40$ when $\mu=16 \%$. Discounts to NAV at lower levels of expected return reflect the probability of failure and the subsequent loss upon liquidation. Premiums to NAV at higher levels of expected return occur because the risk premium is more than enough compensation for the volatility and probability of failure. For an investor with an unrestricted liquidity option, the hedge fund value, $O_{0,1}$, has no discount to NAV. The investor only remains invested when the expected holding period return is satisfactory, taking into account the expected return in the normal regime and the probability of fund failure. As with the case of the no liquidity option, the value of the hedge fund increases with expected return with $O_{0,1}$ ranging from $\$ 100.02$ when $\mu=8 \%$ to $\$ 121.40$ when $\mu=16 \%$. 
Insert Table VII about here.

When expected returns are high, hedge fund value with a lockup, $O_{L, 0,1}$, is not substantially different from the unrestricted hedge fund value $O_{0,1}$. The reason for this phenomenon is that when returns are high, the probability that the investor optimally exercises and redeems during the lockup period is extremely low. This is also true for the value of the hedge fund when the investor possesses a liquidity option subject to both lockup and notice period restrictions, $O_{L N P, 0,1}$. For example, in Panel A, when $\mu=12 \%$, the restricted liquidity option with a lockup and notice period is $O_{L N P, 0,1}=\$ 103.32$. Yet an unrestricted liquidity option, $O_{0,1}=\$ 103.55$, makes the cost of the lockup and notice period small at $O_{0,1}-O_{L N P, 0,1}=\$ 0.23$. In contrast, the restriction imposed by a lockup on the hedge fund value causes a noticeable drop from the unrestricted liquidity option value for low expected returns as the probability that exercise is optimal during the lockup period is much higher. For $\mu=10 \%$, the value of the fund with a lockup and a notice period is $O_{L N P, 0,1}=\$ 98.95$ compared to $\$ 100.81$ without the restrictions. As such, the restrictions cost a combined $\$ 1.86$.

Panel B lists values when the fund is 24 months old at time $t=0$ and has a cumulative return equal to the cross-sectional mean at that time. The performance covariate has no impact on failure probability initially. In all cases, the values are lower than in Panel A because the initial failure probability is higher. Panel B reports that investors with an unrestricted liquidity option would optimally exercise immediately so that the value of the fund equals the NAV for all levels of expected return less than $12 \%$. 
The underlying hedge fund value in the case where there is no liquidity option, $H_{0,1}$, warrants further discussion. As discussed in Section II, a common restriction managers can impose, separate from lockups and notice periods, is a gate, which limits the quantity of redemption requests that are accommodated in any period. Gate restrictions are typically invoked when there are an unexpectedly large number of redemptions requested by investors and the fund restricts, usually on a pro-rata basis, the amount of money each investor can receive. In some cases, outright suspensions of redemption ability can disable an investor's real option to withdraw capital. ${ }^{16} 17$ In the limit, gates and suspensions ultimately eliminate the investor's liquidity option. This can be especially costly during times when investment performance is extremely poor and the investor most wishes to redeem. The value of the fund when the redemption option is always suspended when exercised is precisely equal to $H_{0,1}$.

Panel A of Table VII indicates that for relatively low expected returns, such as $\mu=9 \%$, the potential cost of redemption suspensions can be enormous with $H_{0,1}=\$ 85.84$ and $O_{L N P, 0,1}=\$ 96.89$. This implies that the investor is receiving an asset worth about $14 \%$ less than NAV if future withdrawals are always blocked, rather than one worth about par when the liquidity option is honored.

In summary, standard lockup and notice period restrictions on an investor's redemption option pose only modest costs of roughly $1 \%$ of the initial NAV for our base case parameters. In some instances, such as high risk aversion or extremely low recovery rates on failure, lockups

\footnotetext{
${ }^{16}$ See “Ore Hill Closes Fund to Client Withdrawals,” Wall Street Journal 8/23/08.

${ }^{17}$ Gates could be accommodated in our lattice by modifying the payoffs that occur when redemptions are processed after a notice period has elapsed. Instead of the payoff occurring all at once, they occur over a sequence of nodes following the gate. Similarly, suspensions of redemption ability could be represented by extending the lockup beyond the stated horizon.
} 
and notice periods can be more onerous as listed in Table VI. The cost to investors of the suspension of future redemption requests, however, is substantial even under base case parameters exceeding $10 \%$ of an investor's original deposit.

\section{Alternative Measures of the Cost of Illiquidity}

So far, we have computed the costs of notice periods, lockups, and suspensions by assuming that investment in the hedge fund has already been made. An important assumption is that the liquidity options have value because the NAV of the fund does not capture all the relevant valuation variables, especially termination probabilities and liquidation costs. In this section, we assume that at initiation, the investor is indifferent from investing and not investing in the fund. That is, the initial NAV is the fair value to the investor.

We calibrate our numerical examples so that the investor's valuation of $H_{0,1}$, the most conservative hedge fund value assuming no liquidity option, exactly equals the initial NAV of $\$ 100$. We achieve this by selecting appropriate combinations of expected returns and volatilities. Table VIII selects these parameters so that an investor with no liquidity option values a fund with age $=0$ at time $t=0$ at par. Each row of Table VIII corresponds to a different combination of $\mu$ and $\sigma$. By construction, the value of $H_{0,1}$ for all rows is 100 .

Insert Table VIII about here.

The column labeled $O_{L N P, 0,1}$ reports the value of the fund if the investor is granted a liquidity option restricted by a two-year lockup and a three-month notice period. Moving from the value $H_{0,1}=100$, where no liquidity option is available, to a liquidity option raises the value 
of the hedge fund investment between 3.09\%-3.75\%. The values increase in fund volatility. This is likely due to the increased probability of fund failure with very low returns. Within each row, fund values increase as the restrictions are relaxed. For the lowest level of $\mu$ and $\sigma$, for example, fund value increases from \$103.09-\$103.17 when the notice period is eliminated and from \$103.09-\$103.21 when the lockup is eliminated instead. These results indicate that when investors with no ability to redeem are initially indifferent about investing in a fund, a liquidity option is worth between 3\%-4\% of the initial investment.

Table VIII indicates that the cost of standard restrictions is quite modest in going from $O_{0,1}$, where the investor can redeem at any time, to $O_{L N P, 0,1}$, where the investor is subject to the two-year lockup and three-month notice period. For instance, for $\mu=12.0 \%$ and $\sigma=15.1 \%$, the difference between $O_{L N P, 0,1}$ and $O_{0,1}$ is only $\$ 0.24$.

Another way we can compute shadow costs of illiquidity is to choose combinations of $\mu$ and $\sigma$ so that an investor with an unrestricted liquidity option values the fund at par (i.e., $O_{0,1}=\$ 100$ ). Next, we revalue the hedge fund after imposing various levels of restrictions on liquidity. In each case, we then compute the incremental expected return that is necessary to exactly offset the cost of the restrictions. We report the results of this exercise in Table IX. Listed in each row are the initial expected return and volatility set so that $O_{0,1}=\$ 100$. We report the incremental required returns per annum to compensate the investor for bearing each additional liquidity restriction. Note that the volatilities in Table IX are higher than those volatilities in Table VIII as the calibration is now based on the value of a fund with an unrestricted liquidity option. In Table VIII, the calibration is based on the value of a fund with no liquidity option. 
Insert Table IX about here.

Consider the lowest level of $\mu$ and $\sigma$ in Table IX. Starting from the farthest right-hand column, the imposition of a three-month notice period requires an additional $0.41 \%$ expected return per year for the investor to be compensated. In contrast, a two-year lockup requires an additional 2.65\% per year. Again, in this example, lockups are significantly more costly than notice periods. When the liquidity option is completely eliminated, the necessary increase in expected return to adequately compensate the investor is $4.36 \%$ per year. All these liquidity costs become larger as volatility increases.

In summary, for an investor who disregards liquidity restrictions and initially values the fund fairly at par, elimination of the ability to redeem is equivalent to an expected return shortfall of over $4 \%$ per year. This result illustrates the tremendous cost imposed on investors when managers exercise their option to prohibit investor withdrawals.

\section{Conclusion}

We model the investor's decision to redeem capital from a hedge fund as a real option and develop a methodology to value the cost of lockups and notice periods to a risk-averse CRRA investor. An investor who is always able to redeem from the fund and receive the prevailing NAV has an unrestricted liquidity option. Lockups and notice periods are exercise restrictions that reduce the value of the liquidity option. The cost of the restrictions is estimated by the resulting reduction in the value of the liquidity option that investors possess. 
We value the liquidity options using a lattice to account for the possibility that early exercise and incorporates time-varying probabilities of fund failure that vary with fund age and fund performance. We find for an investment already made in a hedge fund, typical parameter values can generate costs of $1 \%$ of the initial NAV for a two-year lockup and a three-month notice period for a risk aversion level of three. For this level of risk aversion, this cost is well below the liquidity premium that hedge fund investors gain as reported by Aragon (2007). Thus, hedge funds are able to earn returns that more than compensate investors for the cost of lockups and notice periods. For more risk-averse investors, however, the cost of restrictions can be much higher and the tradeoff between the cost and benefit of illiquidity is less clear. We confirm that the cost of restrictions substantially increases when the failure rate increases, when the proportion of assets retained upon fund failure declines, and when investors become more risk averse.

When fund managers can unilaterally suspend an investor's real option to redeem, we demonstrate that the cost of illiquidity can exceed $10 \%$ of initial fund NAV. This result suggests that hedge fund investors should be more concerned about the discretion asserted by fund managers in their partnership agreement and the conditions under which redemption suspensions can be imposed, rather than by the standard terms of lockup and notice periods. 


\section{References}

Ackermann, C., R. McEnally, and D. Ravnescraft, 1999, "The Performance of Hedge Funds: Risk, Return, and Incentives," Journal of Finance 54, 833-874.

Aragon, G.O., 2007, "Share Restrictions and Asset Pricing: Evidence from the Hedge Fund Industry," Journal of Financial Economics 83, 33-58.

Asness, C., R. Krail, and J. Liew, 2001, "Do Hedge Funds Hedge?" Journal of Portfolio Management 28, 6-19.

Berk, J.B. and R.H. Stanton, 2007, "Managerial Ability, Compensation, and the Closed-End Fund Discount," Journal of Finance 62, 529-556.

Bollen, N.P.B. and V. Pool, 2008, "Conditional Return Smoothing in the Hedge Fund Industry," Journal of Financial and Quantitative Analysis 43, 267-298.

Bollen, N.P.B., T. Smith, and R.E. Whaley, 2004, "Modeling the Bid/Ask Spread: Measuring the Inventory-Holding Premium," Journal of Financial Economics 72, 97-41.

Brown, S.J., W.N. Goetzmann, and J. Park, 2001, "Careers and Survival: Competition and Risk in the Hedge Fund and CTA Industry," Journal of Finance 56, 1,869-1,886. 
Chacko, G.C., J.W. Jurek, and E. Stafford, 2008, "The Price of Immediacy," Journal of Finance 53, 1,253-1,290.

Cherkes, M., J. Sagi, and R. Stanton, 2009, "A Liquidity-Based Theory of Closed-End Funds," Review of Financial Studies 22, 257-297.

Derman, E., 2007, "A Simple Model for the Expected Premium for Hedge Fund Lockups," Journal of Investment Management 5, 5-15.

Derman, E., K.S. Park, and W. Whitt, 2009, "Markov Chain Models to Estimate the Premium for Extended Hedge Fund Lockups," Wilmott Journal 1, 263-293.

Detemple, J. and S. Sundaresan, 1999, "Non-traded Asset Valuation with Portfolio Constraints," Review of Financial Studies 12, 835-872.

Ding, B., M. Getmansky, B. Liang, and R. Wermers, 2007, "Investor Flows and Share Restrictions in the Hedge Fund Industry," University of Massachusetts Working Paper.

Duffie, D., K. Wang, and L. Saita, 2007, "Multi-Period Corporate Default Prediction with Stochastic Covariates," Journal of Financial Economics 83, 635-665.

Garleanu, N., 2009, "Pricing and Portfolio Choice in Illiquid Markets," Journal of Economic Theory 144, 532-564. 
Getmansky, M., A.W. Lo, and I. Makarov, 2004, "An Econometric Model of Serial Correlation and Illiquidity in Hedge Fund Returns," Journal of Financial Economics 74, 529-609.

Grecu, A., B.G. Malkiel, and A. Saha, 2007, "Why Do Hedge Funds Stop Reporting Their Performance?" Journal of Portfolio Management 34, 119-126.

Gregoriou, G.N., 2002, "Hedge Fund Survival Lifetimes," Journal of Asset Management 3, 237252.

Hull, J. and A. White, 1993, "Numerical Procedures for Implementing Term Structure Models I: Single-Factor Models," Journal of Derivatives 2, 9-16.

Hull, J. and A. White, 2004, "How to Value Employee Stock Options," Financial Analysts Journal 60, 114-119.

Jagannathan, R., A. Malakhov, and D. Novikov, 2010, "Do Hot Hands Persist Among Hedge Fund Managers? An Empirical Evaluation," Journal of Finance 65, 217-255.

Kahl, M., J. Liu, and F.A. Longstaff, 2003, "Paper Millionaires: How Valuable is Stock to a Stockholder Who is Restricted from Selling It?" Journal of Financial Economics 67, 385-410. 
Kalbfleisch, J.D. and R.L. Prentice, 2002, The Statistical Analysis of Failure Time Data, $2^{\text {nd }}$ edition, Hoboken, NJ, John Wiley \& Sons.

Kulatilaka, N. and A. Marcus, 1994, "Valuing Employee Stock Options," Financial Analysts Journal 50, 46-56.

Lerner, J. and A. Schoar, 2004, "The Illiquidity Puzzle: Theory and Evidence from Private Equity," Journal of Financial Economics 72, 3-40.

Liang, B., 2000, "Hedge Funds: The Living and the Dead," Journal of Financial and Quantitative Analysis 35, 309-326.

Longstaff, F.A., 1995, "How Much Can Marketability Affect Security Values?" Journal of Finance 50, 1,767-1,774.

Longstaff, F.A., 2009, "Portfolio Claustrophobia: Asset Pricing in Markets with Illiquid Assets," American Economic Review 99, 1,119-1,144.

Margrabe, W., 1978, "The Value of an Option to Exchange One Asset for Another," Journal of Finance 33, 177-186.

Murphy, K., 1999, "Executive Compensation," in O. Ashenfelter and D. Card, Eds., Handbook of Labor Economics, Amsterdam, North-Holland. 
Ramadorai, T., 2008, "The Secondary Market for Hedge Funds and the Closed-Hedge Fund Premium, University of Oxford Working Paper.

Scholes, M.S., 2000, "The Near Crash of 1998: Crisis and Risk Management," American Economic Association Papers and Proceedings 90, 17-21.

Sharpe, W.F., 1992, "Asset Allocation: Management Style and Performance Management," Journal of Portfolio Management 18, 7-19. 


\section{Table I. Nomenclature}

Listed are the symbols used to denote hedge fund value with and without a liquidity option, the value of liquidity options, and the cost of redemption restrictions.

$$
\begin{array}{ll}
H & =\text { Fund value with no liquidity option } \\
O & =\text { Fund value with unrestricted liquidity option } \\
O_{L} & =\text { Fund value subject to lockup } \\
O_{N P} & =\text { Fund value subject to notice period } \\
O_{L N P} & =\text { Fund value subject to lockup and notice period } \\
O-H & =\text { Value of unrestricted liquidity option } \\
O_{L}-H & =\text { Value of liquidity option subject to lockup } \\
O_{N P}-H & =\text { Value of liquidity option subject to notice period } \\
O_{L N P}-H & =\text { Value of liquidity option subject to lockup and notice period } \\
O-O_{L} & =\text { Cost of lockup } \\
O-O_{N P} & =\text { Cost of notice period } \\
O-O_{L N P} & =\text { Combined cost of lockup and notice period }
\end{array}
$$




\section{Table II. Durations}

Listed is the interquartile range of durations in months of hedge funds in the 2005 CISDM hedge fund database.

\begin{tabular}{lcccc}
\hline & $\begin{array}{c}\text { No. of } \\
\text { Funds }\end{array}$ & $\mathbf{2 5}^{\text {th }}$ & $\mathbf{5 0}^{\text {th }}$ & $\mathbf{7 5}^{\text {th }}$ \\
\hline Live & 4,272 & 20 & 44 & 84 \\
Defunct & 4,260 & 25 & 47 & 80 \\
All & 8,532 & 23 & 45 & 82 \\
\hline
\end{tabular}




\section{Table III. Summary Statistics}

Listed are annualized summary statistics of monthly returns of funds in the 2005 CISDM database. Only funds with at least 24 observations are included. Fund types are hedge funds (HF), funds of funds (FOF), commodity trading advisors (CTA), and commodity pool operators (CPO). Summary statistics include mean $(\mu)$, standard deviation $(\sigma)$, Sharpe (1992) ratio (SR), skewness (Skew), and excess kurtosis (Kurt). Monthly means are annualized by multiplying by 12 and monthly standard deviations are annualized by multiplying by $\sqrt{12}$.

\begin{tabular}{|c|c|c|c|c|c|c|}
\hline \multicolumn{7}{|c|}{ Panel A. Defunct Funds } \\
\hline Type & No. of Funds & $\mu$ & $\sigma$ & $S R$ & Skew & Kurt \\
\hline $\mathrm{HF}$ & 1,685 & $11.86 \%$ & $18.59 \%$ & 0.63 & -0.02 & 4.14 \\
\hline FOF & 388 & $7.22 \%$ & $9.65 \%$ & 0.58 & -0.31 & 4.13 \\
\hline CTA & 548 & $12.83 \%$ & $23.64 \%$ & 0.31 & 0.64 & 3.87 \\
\hline $\mathrm{CPO}$ & 666 & $7.29 \%$ & $19.46 \%$ & 0.15 & 0.34 & 3.60 \\
\hline All & 3,287 & $10.55 \%$ & $18.56 \%$ & 0.47 & 0.13 & 3.99 \\
\hline \multicolumn{7}{|c|}{ Panel B. Live Funds } \\
\hline Type & No. of Funds & $\mu$ & $\sigma$ & $S R$ & Skew & Kurt \\
\hline $\mathrm{HF}$ & 1,450 & $13.87 \%$ & $12.43 \%$ & 1.27 & 0.15 & 3.55 \\
\hline FOF & 1,025 & $8.54 \%$ & $5.91 \%$ & 1.26 & -0.24 & 2.50 \\
\hline CTA & 303 & $15.11 \%$ & $20.62 \%$ & 0.60 & 0.54 & 2.88 \\
\hline $\mathrm{CPO}$ & 245 & $10.76 \%$ & $18.54 \%$ & 0.47 & 0.46 & 2.01 \\
\hline All & 3,023 & $11.93 \%$ & $11.53 \%$ & 1.14 & 0.08 & 3.00 \\
\hline \multicolumn{7}{|c|}{ Panel C. All Funds } \\
\hline Type & No. of Funds & $\mu$ & $\sigma$ & $S R$ & Skew & Kurt \\
\hline $\mathrm{HF}$ & 3,135 & $12.79 \%$ & $15.74 \%$ & 0.92 & 0.06 & 3.87 \\
\hline FOF & 1,413 & $8.18 \%$ & $6.94 \%$ & 1.08 & -0.26 & 2.94 \\
\hline CTA & 851 & $13.64 \%$ & $22.57 \%$ & 0.41 & 0.60 & 3.52 \\
\hline $\mathrm{CPO}$ & 911 & $8.22 \%$ & $19.21 \%$ & 0.23 & 0.37 & 3.17 \\
\hline All & 6,310 & $11.21 \%$ & $15.19 \%$ & 0.79 & 0.11 & 3.51 \\
\hline
\end{tabular}




\section{Table IV. Duration Parameters}

Listed are parameter estimates for the following hazard rate to model the probability of hedge fund failure:

$$
\lambda(t ; z)=\lambda q(\lambda t)^{q-1} /\left[1+(\lambda t)^{q}\right] \exp (z \beta)
$$

where $\lambda, q$, and $\beta$ are parameters, $t$ is the age of the fund, and $z$ is the value of a performance score which equals the number of cross-sectional standard deviations the fund's cumulative return is from the cross-sectional mean. Parameters are estimated by maximum likelihood using the 2005 CISDM hedge fund database.

\begin{tabular}{llll}
\hline \multicolumn{4}{c}{ Parameter } \\
\hline Estimate & $\boldsymbol{\lambda}$ & $\boldsymbol{q}$ & $\boldsymbol{\beta}$ \\
Std Error & $0.0129 * * *$ & $1.6517^{* * *}$ & $-0.3237^{* * *}$ \\
\hline & 0.0002 & 0.0200 & 0.0059 \\
\hline
\end{tabular}

***Significant at the 0.01 level. 


\section{Table V. Combined Cost of Lockup and Notice Period}

Listed are the combined costs of lockups and notice periods of different lengths, in months, per share of a hedge fund with an initial NAV of $\$ 100$. Returns are normally distributed with an annual volatility of $15 \%$ and expected return of $12 \%$. Fund failures arrive randomly following a log-logistic distribution. Upon failure, NAV drops $25 \%$ and the investor receives the remaining assets as a liquidating dividend. Panel A presents results for new funds and Panel B reports results for funds with an initial age of 24 months, both with risk aversion $\gamma=3$.

\begin{tabular}{lccccc}
\hline \multicolumn{5}{c}{ Panel A. Age $=0$} \\
\hline \multirow{2}{*}{ Notice } & $\mathbf{1 2}$ & $\mathbf{2 4}$ & $\mathbf{3 6}$ & $\mathbf{4 8}$ & $\mathbf{6 0}$ \\
\cline { 2 - 6 } 1 & 0.01 & 0.15 & 0.68 & 1.39 & 2.03 \\
2 & 0.03 & 0.19 & 0.74 & 1.45 & 2.08 \\
3 & 0.04 & 0.23 & 0.80 & 1.51 & 2.13 \\
4 & 0.05 & 0.27 & 0.86 & 1.57 & 2.18 \\
5 & 0.07 & 0.31 & 0.92 & 1.62 & 2.22 \\
\hline & & Panel B. Age $=24$ & & \\
\hline & $\mathbf{1 2}$ & $\mathbf{2 4}$ & $\mathbf{3 6}$ & $\mathbf{4 8}$ & $\mathbf{6 0}$ \\
\hline 1 & 0.15 & 0.64 & 1.21 & 1.69 & 2.06 \\
2 & 0.19 & 0.69 & 1.26 & 1.73 & 2.09 \\
3 & 0.23 & 0.74 & 1.30 & 1.76 & 2.11 \\
4 & 0.27 & 0.80 & 1.35 & 1.80 & 2.14 \\
5 & 0.31 & 0.85 & 1.39 & 1.83 & 2.16 \\
\hline
\end{tabular}




\section{Table VI. Liquidity Option Values and Restriction Costs}

Listed in Panel A are unrestricted liquidity option values for a risk-averse investor with CRRA preferences invested in a fund with an initial NAV of $\$ 100$ and a ten-year life. Panel B reports the combined costs of a two-year lockup and a three-month notice period. The base case has returns that are normally distributed with an annual volatility of $15 \%$ and an expected return as listed. Fund failures arrive randomly following a log-logistic distribution. The hazard rate $\lambda$ parameter is estimated from the data. Upon failure, the investor receives $75 \%$ of the remaining assets as a liquidating dividend. Panels A1 and B1 presents results when the hazard rate is scaled by the factor listed. Panels A2 and B2 report results when the percentage of assets recovered upon failure, $l$, are varied as listed. Panels A3 and B3 display results when volatility is varied as listed. Panels A4 and B4 presents results when risk aversion is varied as listed.

\begin{tabular}{|c|c|c|c|c|c|c|c|c|c|c|c|}
\hline & & \multicolumn{5}{|c|}{ A. Liquidity Option Value } & \multicolumn{5}{|c|}{ B. Restriction Cost } \\
\hline \multirow{7}{*}{ 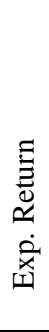 } & & \multicolumn{5}{|c|}{ A1. Risk Aversion Parameter $\lambda$} & \multicolumn{5}{|c|}{ B1. Risk Aversion Parameter $\lambda$} \\
\hline & & $50 \%$ & $100 \%$ & $150 \%$ & $200 \%$ & $250 \%$ & $50 \%$ & $100 \%$ & $150 \%$ & $200 \%$ & $250 \%$ \\
\hline & $8 \%$ & 11.39 & 18.62 & 21.19 & 22.38 & 23.05 & 1.14 & 5.14 & 9.02 & 12.21 & 14.69 \\
\hline & $10 \%$ & 1.81 & 10.36 & 14.72 & 17.11 & 18.61 & 0.02 & 1.86 & 5.66 & 9.07 & 11.81 \\
\hline & $12 \%$ & 0.00 & 3.40 & 8.58 & 11.95 & 14.20 & 0.00 & 0.23 & 2.81 & 6.13 & 9.00 \\
\hline & $14 \%$ & 0.00 & 0.22 & 3.24 & 7.06 & 9.91 & 0.00 & 0.02 & 0.87 & 3.52 & 6.34 \\
\hline & $16 \%$ & 0.00 & 0.00 & 0.43 & 2.82 & 5.85 & 0.00 & 0.00 & 0.13 & 1.48 & 3.91 \\
\hline \multirow{7}{*}{ 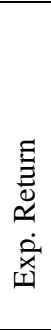 } & & \multicolumn{5}{|c|}{ A2. Loss Parameter I } & \multicolumn{5}{|c|}{ B2. Loss Parameter I } \\
\hline & & $50 \%$ & $60 \%$ & $70 \%$ & $80 \%$ & $90 \%$ & $50 \%$ & $60 \%$ & $70 \%$ & $80 \%$ & $90 \%$ \\
\hline & $8 \%$ & 43.71 & 33.34 & 23.41 & 13.96 & 5.08 & 18.44 & 11.87 & 7.06 & 3.49 & 0.88 \\
\hline & $10 \%$ & 37.81 & 26.35 & 15.48 & 5.58 & 0.01 & 15.09 & 8.34 & 3.59 & 0.62 & 0.00 \\
\hline & $12 \%$ & 31.74 & 19.38 & 8.13 & 0.46 & 0.00 & 11.83 & 5.17 & 1.11 & 0.03 & 0.00 \\
\hline & $14 \%$ & 25.62 & 12.70 & 2.37 & 0.00 & 0.00 & 8.74 & 2.58 & 0.16 & 0.00 & 0.00 \\
\hline & $16 \%$ & 19.57 & 6.68 & 0.18 & 0.00 & 0.00 & 5.93 & 0.88 & 0.02 & 0.00 & 0.00 \\
\hline \multirow{7}{*}{ 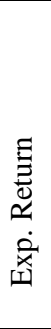 } & & \multicolumn{5}{|c|}{ A3. Volatility Parameter $\sigma$} & \multicolumn{5}{|c|}{ B3. Volatility Parameter $\sigma$} \\
\hline & & $5 \%$ & $10 \%$ & $15 \%$ & $20 \%$ & $25 \%$ & $5 \%$ & $10 \%$ & $15 \%$ & $20 \%$ & $25 \%$ \\
\hline & $8 \%$ & 5.92 & 10.52 & 18.62 & 29.50 & 41.34 & 0.54 & 1.89 & 5.14 & 10.33 & 16.56 \\
\hline & $10 \%$ & 0.16 & 3.24 & 10.36 & 21.47 & 34.53 & 0.01 & 0.14 & 1.86 & 6.50 & 13.02 \\
\hline & $12 \%$ & 0.00 & 0.04 & 3.40 & 13.24 & 27.11 & 0.00 & 0.01 & 0.23 & 2.92 & 9.31 \\
\hline & $14 \%$ & 0.00 & 0.00 & 0.22 & 5.94 & 19.10 & 0.00 & 0.00 & 0.02 & 0.70 & 5.46 \\
\hline & $16 \%$ & 0.00 & 0.00 & 0.00 & 1.29 & 11.30 & 0.00 & 0.00 & 0.00 & 0.11 & 2.26 \\
\hline \multirow{7}{*}{ 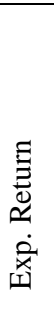 } & & \multicolumn{5}{|c|}{ A4. Hazard Rate Parameter $\gamma$} & \multicolumn{5}{|c|}{ B4. Hazard Rate Parameter $\gamma$} \\
\hline & & 1.00 & 2.25 & 3.50 & 4.75 & 6.00 & 1.00 & 2.25 & 3.50 & 4.75 & 6.00 \\
\hline & $8 \%$ & 6.03 & 14.29 & 21.29 & 27.35 & 32.97 & 0.46 & 3.03 & 6.63 & 10.27 & 13.70 \\
\hline & $10 \%$ & 0.26 & 5.92 & 13.14 & 19.50 & 25.30 & 0.03 & 0.53 & 3.07 & 6.60 & 10.26 \\
\hline & $12 \%$ & 0.00 & 0.58 & 5.93 & 12.11 & 17.81 & 0.00 & 0.04 & 0.71 & 3.31 & 6.77 \\
\hline & $14 \%$ & 0.00 & 0.00 & 1.10 & 5.91 & 11.17 & 0.00 & 0.00 & 0.07 & 1.02 & 3.71 \\
\hline & $16 \%$ & 0.00 & 0.00 & 0.03 & 1.68 & 5.82 & 0.00 & 0.00 & 0.01 & 0.14 & 1.47 \\
\hline
\end{tabular}




\section{Table VII. Hedge Fund Values}

Listed in Panel A are values per share of a new hedge fund with an initial NAV of \$100 and a ten-year life. Returns are normally distributed with an annual volatility of $15 \%$ and an expected return as listed. Fund failures arrive randomly following a loglogistic distribution. Upon failure, NAV drops $25 \%$ and the investor receives the remaining assets as a liquidating dividend. The investor has a risk aversion parameter $\gamma=3$. The five columns are: 1 ) the value to an investor with no liquidity option, $H_{0,1} ; 2$ ) the value to an investor with a liquidity option subject to a two-year lockup and a three-month notice period, $O_{L N P, 0,1}$; 3 ) the value subject only to a lockup, $\left.O_{L, 0,1} ; 4\right)$ the value subject only to a notice period, $O_{N P, 0,1}$; and 5) the value when no restrictions are in place, $O_{0,1}$. Panel B presents values when the fund is 24 months old at the time of investment and has a cumulative return at that time equal to the cross-sectional mean.

\begin{tabular}{|c|c|c|c|c|c|}
\hline \multicolumn{6}{|c|}{ Panel A. Age $=0$} \\
\hline$\mu$ & $H_{0,1}$ & $O_{L N P, 0,1}$ & $O_{L, 0,1}$ & $O_{N P, 0,1}$ & $O_{0,1}$ \\
\hline $8 \%$ & 81.40 & 94.88 & 95.70 & 99.96 & 100.02 \\
\hline $9 \%$ & 85.84 & 96.89 & 97.53 & 100.24 & 100.25 \\
\hline $10 \%$ & 90.45 & 98.95 & 99.40 & 100.79 & 100.81 \\
\hline $11 \%$ & 95.22 & 101.06 & 101.32 & 101.81 & 101.84 \\
\hline $12 \%$ & 100.15 & 103.32 & 103.43 & 103.52 & 103.55 \\
\hline $13 \%$ & 105.24 & 106.34 & 106.39 & 106.36 & 106.41 \\
\hline $14 \%$ & 110.48 & 110.68 & 110.71 & 110.68 & 110.71 \\
\hline $15 \%$ & 115.87 & 115.89 & 115.89 & 115.89 & 115.89 \\
\hline $16 \%$ & 121.40 & 121.40 & 121.40 & 121.40 & 121.40 \\
\hline \multicolumn{6}{|c|}{ Panel B. Age $=24$} \\
\hline$\mu$ & $H_{0,1}$ & $O_{L N P, 0,1}$ & $O_{L, 0,1}$ & $O_{N P, 0,1}$ & $O_{0,1}$ \\
\hline $8 \%$ & 81.30 & 92.29 & 93.06 & 99.12 & 100.00 \\
\hline $9 \%$ & 85.29 & 94.05 & 94.67 & 99.37 & 100.00 \\
\hline $10 \%$ & 89.34 & 95.84 & 96.30 & 99.61 & 100.00 \\
\hline $11 \%$ & 93.45 & 97.66 & 97.97 & 99.86 & 100.00 \\
\hline $12 \%$ & 97.61 & 99.55 & 99.70 & 100.25 & 100.30 \\
\hline $13 \%$ & 101.81 & 102.18 & 102.24 & 102.25 & 102.30 \\
\hline $14 \%$ & 106.03 & 106.06 & 106.06 & 106.06 & 106.06 \\
\hline $15 \%$ & 110.28 & 110.28 & 110.28 & 110.28 & 110.28 \\
\hline $16 \%$ & 114.53 & 114.53 & 114.53 & 114.53 & 114.53 \\
\hline
\end{tabular}




\section{Table VIII. Incremental Hedge Fund Values}

Listed are values per share of a new hedge fund with an initial NAV of $\$ 100$ and a ten-year life. The combinations of expected return, $\mu$, and volatility, $\sigma$, are chosen so that the value to an investor with no liquidity option is equal to par. Returns are normally distributed with an expected return as listed. Annual volatility is adjusted so that the value to an investor with no liquidity option is equal to the initial NAV. Fund failures arrive randomly following a log-logistic distribution. Upon failure, NAV drops $25 \%$ and the investor receives the remaining assets as a liquidating dividend. The investor has a risk aversion parameter $\gamma=3$. The five columns are: 1 ) the value to an investor with no liquidity option, $H_{0,1} ; 2$ ) the value to an investor with a liquidity option subject to a two-year lockup and a three-month notice period, $O_{L N P, 0,1}$; 3 ) the value subject only to a lockup, $\left.O_{L, 0,1} ; 4\right)$ the value subject only to a notice period, $O_{N P, 0,1}$; and 5) the value when no restrictions are in place, $O_{0,1}$.

\begin{tabular}{rcccccc}
\hline & & \multicolumn{5}{c}{ Liquidity Option } \\
\cline { 3 - 7 } $\boldsymbol{\mu}$ & $\boldsymbol{\sigma}$ & $H_{0,1}$ & $O_{L N P, 0,1}$ & $O_{L, 0,1}$ & $O_{N P, 0,1}$ & $O_{0,1}$ \\
\hline $10.0 \%$ & $10.0 \%$ & 100.00 & 103.09 & 103.17 & 103.21 & 103.23 \\
$11.0 \%$ & $12.8 \%$ & 100.00 & 103.17 & 103.26 & 103.33 & 103.36 \\
$12.0 \%$ & $15.1 \%$ & 100.00 & 103.25 & 103.36 & 103.45 & 103.49 \\
$13.0 \%$ & $17.0 \%$ & 100.00 & 103.34 & 103.46 & 103.57 & 103.62 \\
$14.0 \%$ & $18.8 \%$ & 100.00 & 103.42 & 103.56 & 103.69 & 103.75 \\
$15.0 \%$ & $20.4 \%$ & 100.00 & 103.51 & 103.66 & 103.81 & 103.88 \\
$16.0 \%$ & $22.0 \%$ & 100.00 & 103.59 & 103.76 & 103.92 & 104.00 \\
$17.0 \%$ & $23.4 \%$ & 100.00 & 103.67 & 103.85 & 104.03 & 104.12 \\
$18.0 \%$ & $24.7 \%$ & 100.00 & 103.75 & 103.94 & 104.14 & 104.24 \\
\hline & & & & & &
\end{tabular}




\section{Table IX. Incremental Required Returns}

Listed are the incremental returns required to offset the cost of liquidity restrictions in a new hedge fund with an initial NAV of $\$ 100$ and a ten-year life. Base case returns are normally distributed with an expected return as listed. Annual volatility is adjusted so that the value to an investor with an unrestricted liquidity option is equal to the initial NAV. Fund failures arrive randomly following a log-logistic distribution. Upon failure, NAV drops $25 \%$ and the investor receives the remaining assets as a liquidating dividend. The investor has a risk aversion parameter $\gamma=3$. The four columns are the additional expected return required to offset restrictions for: 1 ) an investor with no liquidity option, $H_{0,1} ; 2$ ) an investor with a liquidity option subject to a two-year lockup and a three-month notice period, $\left.O_{L N P, 0,1} ; 3\right)$ an investor with a liquidity option subject only to a lockup, $O_{L, 0,1}$; and 4) an investor with a liquidity option subject only to a notice period, $O_{N P, 0,1}$.

\begin{tabular}{rccccc}
\hline & & \multicolumn{4}{c}{ Liquidity Option } \\
\cline { 3 - 6 } $\boldsymbol{\mu}$ & $\boldsymbol{\sigma}$ & $H_{0,1}$ & $O_{L N P, 0,1}$ & $O_{L, 0,1}$ & $O_{N P, 0,1}$ \\
\hline $10.0 \%$ & $19.4 \%$ & $4.36 \%$ & $2.84 \%$ & $2.65 \%$ & $0.41 \%$ \\
$11.0 \%$ & $21.1 \%$ & $4.42 \%$ & $2.88 \%$ & $2.69 \%$ & $0.41 \%$ \\
$12.0 \%$ & $22.6 \%$ & $4.47 \%$ & $2.92 \%$ & $2.72 \%$ & $0.42 \%$ \\
$13.0 \%$ & $24.1 \%$ & $4.53 \%$ & $2.95 \%$ & $2.75 \%$ & $0.42 \%$ \\
$14.0 \%$ & $25.4 \%$ & $4.58 \%$ & $2.99 \%$ & $2.79 \%$ & $0.42 \%$ \\
$15.0 \%$ & $26.7 \%$ & $4.64 \%$ & $3.02 \%$ & $2.82 \%$ & $0.42 \%$ \\
$16.0 \%$ & $28.0 \%$ & $4.70 \%$ & $3.06 \%$ & $2.85 \%$ & $0.43 \%$ \\
$17.0 \%$ & $29.2 \%$ & $4.75 \%$ & $3.10 \%$ & $2.88 \%$ & $0.43 \%$ \\
$18.0 \%$ & $30.3 \%$ & $4.81 \%$ & $3.13 \%$ & $2.92 \%$ & $0.43 \%$ \\
\hline
\end{tabular}




\section{Figure I. The Lattice}

This figure depicts the binomial lattice structure representing the normal regime of a hedge fund. The passage of time is represented by moving from left to right and denoted by an increase in the variable $t$. Horizontal movement represents a positive return. Diagonal downward movement represents a negative return. We refer to the combination of time step $t$ and level $j$ as node $(t, j)$.

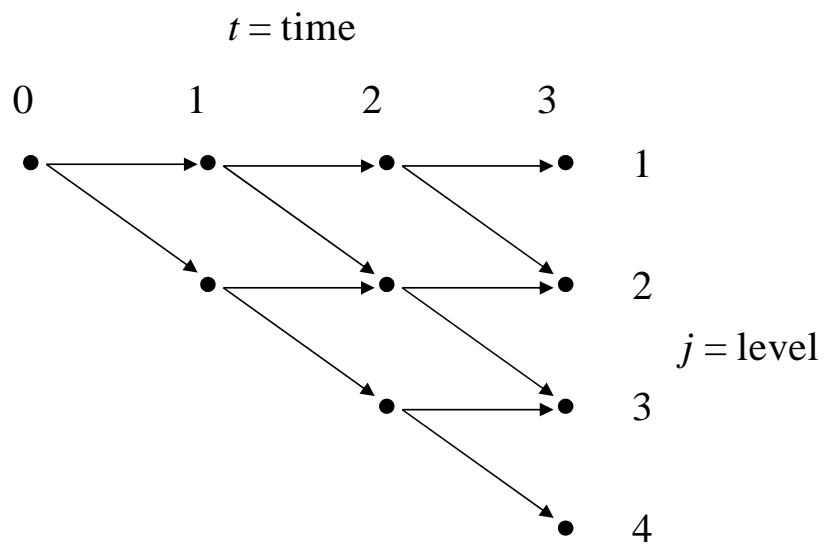


Figure II. Durations of Defunct Funds and History Lengths of Live Funds

Panel A reports the percentage of the 4,260 defunct funds in the 2005 CISDM database with a duration equal to the value on the horizontal axis. Panel B indicates the percentage of the 4,272 live funds in the 2005 CISDM database with history lengths equal to the value on the horizontal axis.

Panel A. Durations of Defunct Funds

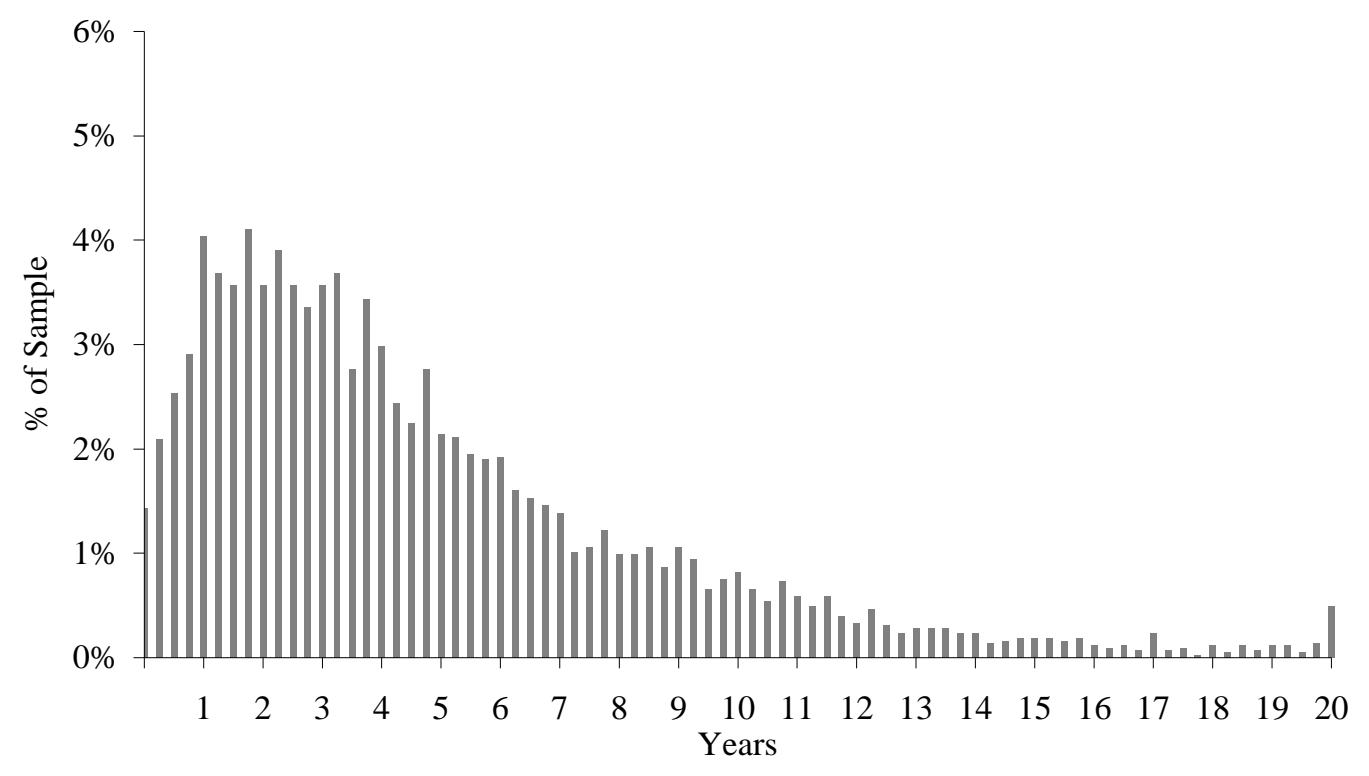

Panel B. History Lengths of Live Funds

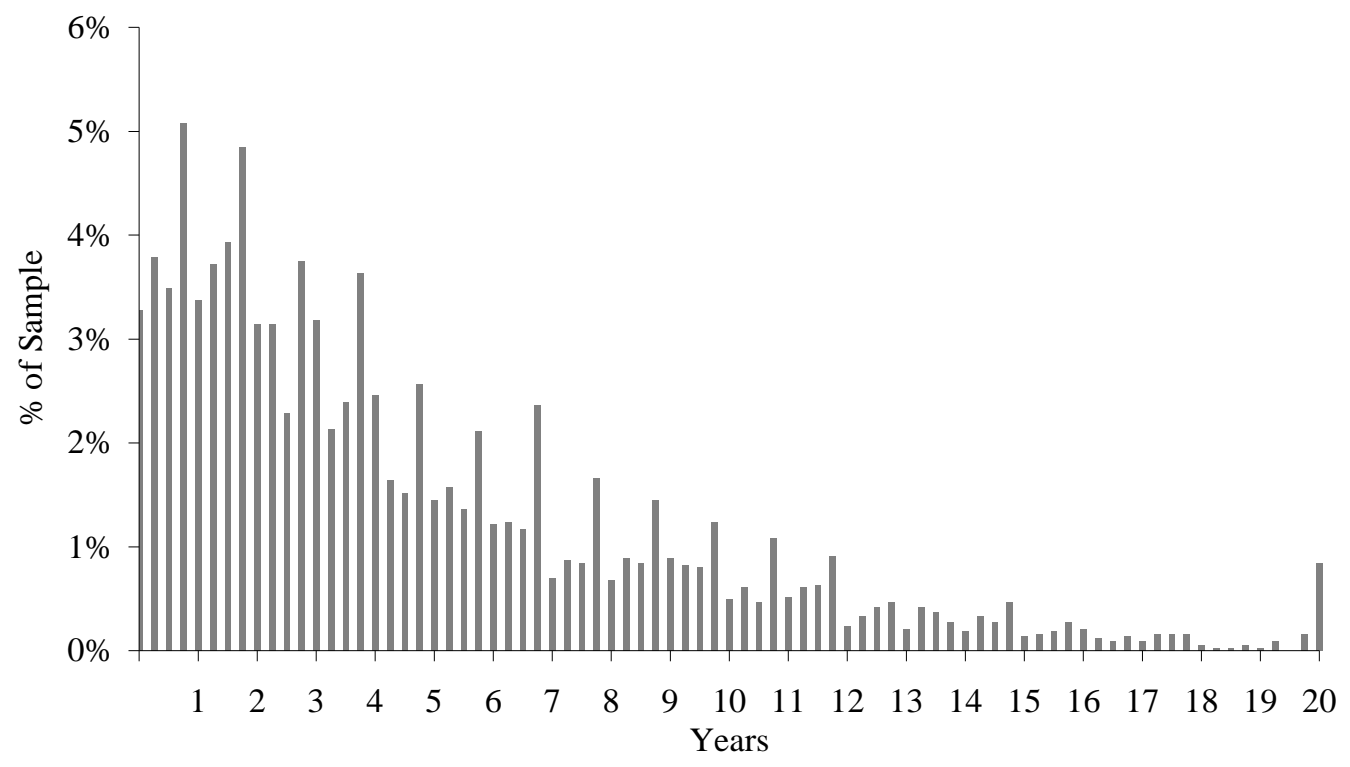




\section{Figure III. Log-logistic Function}

Depicted by hollow squares is the number of defunct hedge funds in the 2005 CISDM hedge fund database with a lifespan equal to the values on the horizontal axis. Represented in bold is the predicted number of hedge funds with a lifespan equal to the values on the horizontal axis. Predicted number of hedge funds at lifespan $t$ equals the hazard rate of the log-logistic function fitted to the data evaluated at $t$ times the number of funds in the database with lifespan greater than or equal to $t$. Data include 8,532 funds with data through 2005.

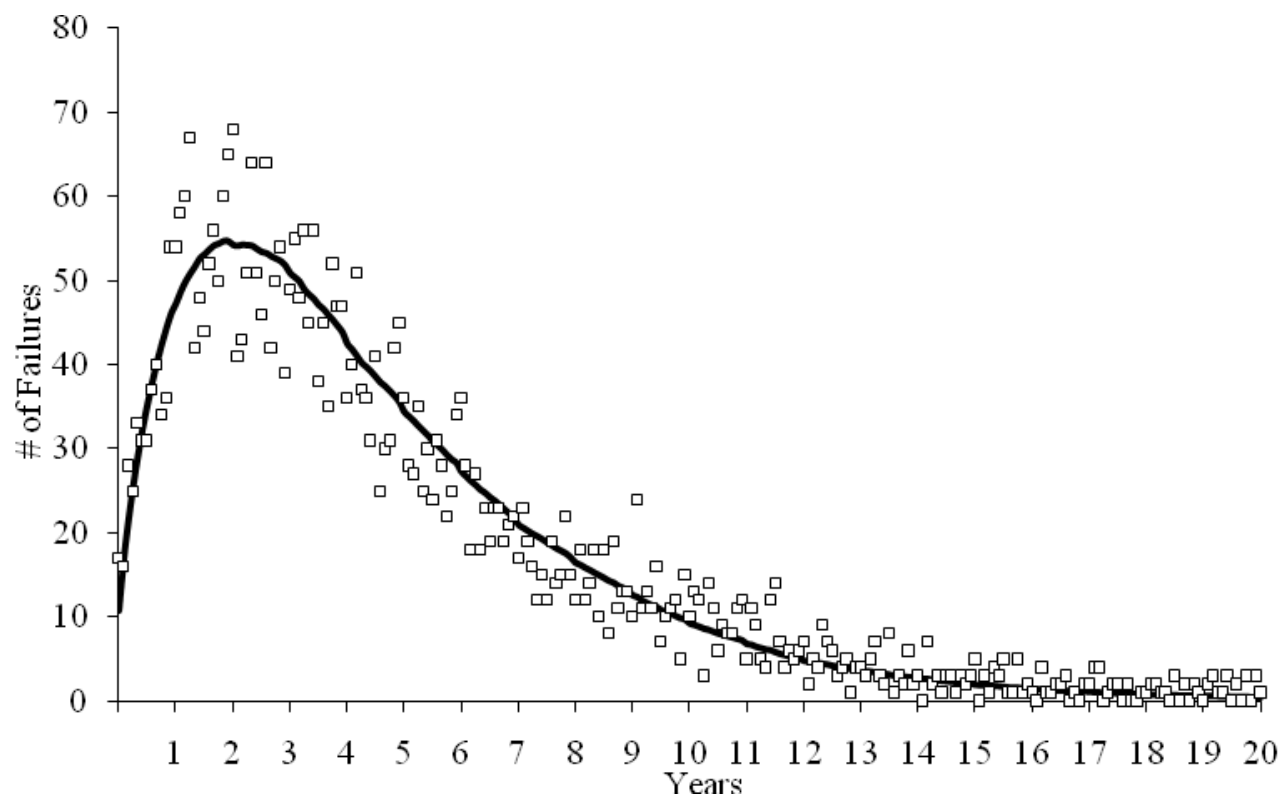

